\title{
Asymmetric Risk Impacts of Chinese Tourists to Taiwan.
}

Instituto

Complutense

de Análisis

Económico

\author{
Chia-Lin Chang \\ Department of Applied Economics \\ Department of Finance National Chung Hsing University, Taiwan \\ Shu-Han Hsu \\ Department of Applied Economics \\ National Chung Hsing University, Taiwan \\ Michael McAleer \\ Department of Finance Asia University, Taiwan and \\ Discipline of Business Analytics University of Sydney Business School, Australia \\ And Econometric Institute, Erasmus School of Economics \\ Erasmus University Rotterdam, The Netherlands and \\ Department of Quantitative Economics \\ Complutense University of Madrid, Spain and \\ Institute of Advanced Sciences Yokohama National University, Japan
}

\begin{abstract}
Since 2008, when Taiwan's President Ma Ying-Jeou relaxed the Cross-Strait policy, China has become Taiwan's largest source of international tourism. In order to understand the risk persistence of Chinese tourists, the paper investigates the short-run and long-run persistence of shocks to the change rate of Chinese tourists to Taiwan. The daily data used for the empirical analysis is from 1 January 2013 to 28 February 2018. McAleer's (2015) fundamental equation in tourism finance is used to link the change rate of tourist arrivals and the change in tourist revenues. Three widely-used univariate conditional volatility models, namely $\operatorname{GARCH}(1,1), \operatorname{GJR}(1,1)$ and $\operatorname{EGARCH}(1,1)$, are used to measure the short-run and long-run persistence of shocks, as well as symmetric, asymmetric and leverage effects. Three different Heterogeneous AutoRegressive (HAR) models, HAR(1), HAR(1,7) $\operatorname{HAR}(1,7,28)$, are considered as alternative mean equations for capturing a variety of long memory effects. The mean equations associated with $\operatorname{GARCH}(1,1), \operatorname{GJR}(1,1)$ and $\operatorname{EGARCH}(1,1)$ are used to analyse the risk persistence of the change in Chinese tourists. The exponential smoothing process is used to adjust the seasonality around the trend in Chinese tourists. The empirical results show asymmetric impacts of positive and negative shocks on the volatility of the change in the number of Group-type and Medical-type tourists, while Individual-type tourists display a symmetric volatility pattern. Somewhat unusually, leverage effects are observed in EGARCH for Medical-type tourists, which shows a negative correlation between shocks in tourist numbers and the subsequent shocks to volatility. For both Group-type and Medical-type tourists, the asymmetric impacts on volatility show that negative shocks have larger effects than do positive shocks. The leverage effect in EGARCH for Medical-type tourists implies that larger shocks would decrease volatility in the change in the numbers of Medical-type tourists. These results suggest that Taiwan tourism authorities should act to prevent the negative shocks for the Group-type and Medical-type Chinese tourists to dampen the shocks that arise from having fewer Chinese tourists to Taiwan.
\end{abstract}

Keywords Asymmetric risk, leverage, risk persistence, tourist revenues, conditional volatility models, Heterogeneous AutoRegressive (HAR) models

JEL Classification G32, C22, C58, Z32, Z33.

Working Paper no 1813

May, 2018

UNIVERSIDAD

COMPLUTENSE

MADRID 


\title{
Asymmetric Risk Impacts of Chinese Tourists to Taiwan*
}

\author{
Chia-Lin Chang \\ Department of Applied Economics \\ Department of Finance \\ National Chung Hsing University, Taiwan \\ Shu-Han Hsu \\ Department of Applied Economics \\ National Chung Hsing University, Taiwan \\ Michael McAleer \\ Department of Finance \\ Asia University, Taiwan \\ and \\ Discipline of Business Analytics \\ University of Sydney Business School, Australia \\ and \\ Econometric Institute, Erasmus School of Economics \\ Erasmus University Rotterdam, The Netherlands \\ and \\ Department of Quantitative Economics \\ Complutense University of Madrid, Spain \\ and \\ Institute of Advanced Sciences \\ Yokohama National University, Japan
}

May 2018

\footnotetext{
* For financial support, the first author wishes to thank the Ministry of Science and Technology (MOST), Taiwan, and the third author acknowledges the Australian Research Council and the Ministry of Science and Technology (MOST), Taiwan.

Corresponding author: michael.mcaleer@gmail.com
} 


\begin{abstract}
Since 2008, when Taiwan's President Ma Ying-Jeou relaxed the Cross-Strait policy, China has become Taiwan's largest source of international tourism. In order to understand the risk persistence of Chinese tourists, the paper investigates the short-run and long-run persistence of shocks to the change rate of Chinese tourists to Taiwan. The daily data used for the empirical analysis is from 1 January 2013 to 28 February 2018. McAleer's (2015) fundamental equation in tourism finance is used to link the change rate of tourist arrivals and the change in tourist revenues. Three widely-used univariate conditional volatility models, namely $\operatorname{GARCH}(1,1), \operatorname{GJR}(1,1)$ and EGARCH(1,1), are used to measure the short-run and long-run persistence of shocks, as well as symmetric, asymmetric and leverage effects. Three different Heterogeneous AutoRegressive (HAR) models, $\operatorname{HAR}(1), \operatorname{HAR}(1,7) \operatorname{HAR}(1,7,28)$, are considered as alternative mean equations for capturing a variety of long memory effects. The mean equations associated with $\operatorname{GARCH}(1,1), \operatorname{GJR}(1,1)$ and $\operatorname{EGARCH}(1,1)$ are used to analyse the risk persistence of the change in Chinese tourists. The exponential smoothing process is used to adjust the seasonality around the trend in Chinese tourists. The empirical results show asymmetric impacts of positive and negative shocks on the volatility of the change in the number of Group-type and Medical-type tourists, while Individual-type tourists display a symmetric volatility pattern. Somewhat unusually, leverage effects are observed in EGARCH for Medical-type tourists, which shows a negative correlation between shocks in tourist numbers and the subsequent shocks to volatility. For both Group-type and Medical-type tourists, the asymmetric impacts on volatility show that negative shocks have larger effects than do positive shocks. The leverage effect in EGARCH for Medical-type tourists implies that larger shocks would decrease volatility in the change in the numbers of Medical-type tourists. These results suggest that Taiwan tourism authorities should act to prevent the negative shocks for the Group-type and Medical-type Chinese tourists to dampen the shocks that arise from having fewer Chinese tourists to Taiwan.
\end{abstract}

Keywords: Asymmetric risk, leverage, risk persistence, tourist revenues, conditional volatility models, Heterogeneous AutoRegressive (HAR) models.

JEL: G32, C22, C58, Z32, Z33. 


\section{Introduction}

One of the most important industries and contributors to the international economy, as well as to Taiwan (Republic of China, R.O.C.), is tourism. According to the report of the Taiwan Tourism Bureau, more than 7.56 million international tourist visitors travelled to Taiwan in 2016, an increase of 0.74\% from 2015. Moreover, receipts from international tourism in Taiwan were estimated to be US\$ 13.38 billion (UNWTO, 2017), contributingg 5.0\% of GDP (US\$ 26.60 billion) and 5.9\% of total employment in 2016 (WTTC, 2017). After China’s tourism reform policy that encouraged Chinese tourists to Taiwan, Chinese tourists (excluding residents from Hong Kong and Macao) accounted for the largest percentage of international tourists to Taiwan since 2010.

There are 3 types of Chinese tourists, namely: Group-type "group-in, group-out" tourists, which were started on 18 July 2008; Individual-type tourists, which were started on 22 June, 2011, although total individual visitors are controlled by a quota; and Medical-type tourists, which started on 1 January 2012. Medical cosmetology tourism for the purpose of physical examinations, treatments or aesthetic medicines are available, but visitors need to furnish proof of NT\$200,000 in personal savings bank account, Platinum, Gold or Infinite Credit Cards, or an annual income of NT\$500,000. However, most Chinese visitors are group-type and individual-type, while very few visitors are of the medical-type. It worth noting that since 2012, there have been more than 50,000 Chinese medical-type tourists to Taiwan, which accounts for almost $90 \%$ of the total international medical-type tourists.

Chinese tourists contribute to daily tourist expenditures in Taiwan, as well as create employment opportunities and increase income. McAleer (2015) showed that the 
growth in income from expenditures by tourist is essentially identical to the returns on financial assets, such as stocks, bonds and any associated financial derivatives. In this paper, we use McAleer's fundamental equation to investigate the growth in income and associated measures of financial risk for the number of Chinese tourists to Taiwan. Based on the fundamental equation in tourism finance, as the daily spending per tourist remains reasonably constant over the sample period, the total number of tourists can be used as an alternative for total daily tourism expenditures.

This paper will focus on three univariate conditional volatility models in financial econometrics to capture the daily risk of changes of Chinese tourists. The first model is GARCH, which provides information for symmetric effects of the persistence of shocks of daily growth in income (Engle, 1982; Bollerslev, 1986). The second model is GJR, an extension of GARCH, which provides information of asymmetric effects of the persistence of shocks of daily growth in income (Glosten et al., 1992). The third model is exponential GARCH (or EGARCH), which is a further adaptation of GARCH, which provides information on the asymmetric effects of the size and sign of shocks in daily growth in income (Nelson, 1990, 1991).

Moreover, in order to capture a variety of long memory effects of shocks, we use the Heterogeneous AutoRegressive (HAR) model as the mean equation for the GARCH, GJR and EGARCH models to analyze the volatility in daily Chinese tourist arrivals to Taiwan.

The daily data provided by the National Immigration Agency of Taiwan is available for the period 1 January 2013 to 28 February 2018. The empirical analysis will focus on three types of Chinese tourists to Taiwan, namely the Group-type, Individual-type, 
and Medical-type tourists.

In order to obtain a more accurate overall impression of the pattern of movements in the numbers of tourist over time, we use the method of exponential smoothing to reduce the seasonality effects, where seasonality is the temporal imbalance in any time series, including tourism (Butler, 1998). In the empirical section, we report the estimation of three conditional volatility models with and without using the seasonal adjustment method.

The remainder of the paper is organized as follows. Section 2 provides a review of the literature. Sections 3 and 4 discuss an overview of the methodology and models that will be used to estimate the volatility of three alternative Chinese tourist arrivals to Taiwan. Section 5 presents the daily Chinese tourist arrivals time series data, and performs unit root tests on daily and exponentially smoothed Chinese tourist arrivals to Taiwan. Section 6 shows the estimated models and empirical results. Section 7 provides some concluding remarks.

\section{Literature Review}

In the field of financial econometrics, univariate conditional volatility models have been widely used to evaluate and predict risk. Shareef and McAleer (2005) borrow the idea from financial econometrics and use univariate asymmetric conditional volatility models to show that the volatility of the monthly growth rate of Japanese tourists to New Zealand can be different between long haul and short haul tourists, to analyse monthly international tourist arrivals for six small island tourism economies (SITEs), namely Barbados, Cyprus, Dominica, Fiji, Maldives and Seychelles. They focus on 
testing the asymmetric effects of conditional volatility of the shocks of monthly international tourist arrivals, and compare the results of the logarithmic and growth rate series. Their empirical results show that Barbados, Cyprus, and Fiji have significant asymmetric effects on the risk of monthly growths of tourist arrivals.

A related study by Shareef and McAleer (2007) examines the asymmetric effects of conditional volatility in the shocks of monthly international tourist arrivals for eight major tourist sources countries to the Maldives, namely Italy, Germany, UK, Japan, France, Switzerland, Austria, and the Netherlands. Their empirical results confirm significant asymmetric long run and short run persistence of unexpected shocks in the international tourist arrivals from the eight major tourism source countries.

Divino and McAleer (2010) use the GJR and EGARCH volatility models to examine the asymmetric effects in the daily growth international tourist arrivals to Peru. Their empirical results, based on the model using the logarithmic series or with log difference series, did not show statistical evidence to support the asymmetry phenomenon in the case of tourist arrivals to Peru.

In order to capture a variety of long memory effects, Chang et al. (2009) use the Heterogeneous Auto-Regressive (HAR) model as the mean equation, associated with the GARCH, GJR and EGARCH models, to analyse the volatility in daily international tourist arrivals to Taiwan. The authors found that asymmetry existed for the simple $\operatorname{HAR}(1)$ model, but not the $\operatorname{HAR}(1,7)$ and $\operatorname{HAR}(1,7,28)$ models, which implies that the conditional volatility estimates are sensitive to the long memory nature of the respective conditional mean specifications. 
A similar framework was applied to daily Korean tourist arrivals to Taiwan by Chang and McAleer (2009), who found significant asymmetric effects in the HAR(1), $\operatorname{HAR}(1,7)$ and $\operatorname{HAR}(1,7,28)$ models. In summary, the empirical results showed that the conditional volatility estimates can have different sensitivities to the long memory nature of the conditional mean specifications across various countries.

Follow a similar modelling stratedy, Chang and McAleer (2012) extend the empirical study to the USA and Japan, and suggest the price effect is an important fact on the determinant of tourist arrivals to Taiwan. Moreover, as in the case of Korea tourists to Taiwan, the empirical results showed significant asymmetric effects in the estimates of the conditional volatility equation.

Another interesting study focuses on a comparison between long haul and short haul risk of the number of international tourists. Chang et al. (2012) use monthly data to examine the persistence of shocks in Japanese tourists to New Zealand and Taiwan, and found that there exist different risks between long haul and short haul international tourist destinations. However, they did not find asymmetric impacts in the volatility of the monthly growth rate of Japanese tourists to Taiwan.

\section{Fundamental Equation in Tourism Finance}

As shown in McAleer (2015), the primary purpose of tourism authorities in the public and private sectors is to achieve high daily returns on total tourism. McAleer (2015) established the fundamental tourism finance equation to connect the growth in the number of tourists and the returns on the associated (tourism) financial asset, which is explained as below: 
Consider equation (1) that total Chinese daily tourist expenditures, $Y_{t}$, are equal to the daily total number of Chinese tourist arrivals, $N_{t}$, times the daily average expenditure by Chinese tourists, $P_{t}$ :

$Y_{t}=N_{t} \times P_{t}$

Taking the logarithm of equation (1) and differentiating $t$ will lead to equations (2) and (3):

$\ln \left(Y_{t}\right)=\ln \left(N_{t}\right)+\ln \left(P_{t}\right)$

$\dot{Y}=\dot{N}+\dot{P}$

where $\dot{Y}=\Delta Y / Y_{t-1}$ is the change rate in total daily Chinese tourism expenditures, as $\Delta Y_{t}=Y_{t}-Y_{t-1}, \dot{N}=\Delta N / N_{t-1}, \dot{N}$ is the net change rate in daily tourist arrivals, $\Delta N=N_{t}-N_{t-1}$, and $\dot{P}=\Delta P / P_{t-1}$ is the change rate of average daily expenditures by Chinese tourists, $\Delta P=P_{t}-P_{t-1}$.

There is little empirical evidence to suggest that the daily average expenditures by tourists changes on a daily basis (McAleer, 2015). Therefore, $\dot{P}$ in equation (3) can be set approximately to zero, so that:

$\dot{Y} \doteqdot \dot{N}$

Equation (4) is the fundamental tourism finance equation, which shows the changes in daily returns in total Chinese tourism are approximately equal to the net change rate in 
daily Chinese tourist arrivals. Based on the fundamental equation (4), if governments and private policy analysts want to achieve a higher daily return on total Chinese tourism, this can be accomplished by encouraging an increase in the daily numbers of Chinese tourists. In the next section, we apply the fundamental equation (4) to three popular univariate conditional volatility models, and forecast the volatility in daily Chinese tourists to Taiwan.

\section{Heterogeneous Autoregressive and Conditional Volatility Models}

In the field of investment finance, $r_{t}$ is the most widely used measure of financial returns, with associated volatility to capture financial risk. Returns are modelled as:

$r_{t}=E\left(r_{t} \mid I_{t-1}\right)+\varepsilon_{t}$

where $r_{t}$ measures financial returns, and $I_{t-1}$ captures the information set that is available at the end of the previous day in order to predict $r_{t}$ and its associated volatility, which is a measure of financial risk.

Financial returns can be regarded as the change rate in total daily Chinese tourism expenditure $r_{t}=\dot{Y}$. Following the fundamental tourism finance equation in equation (4), we have $\dot{Y} \doteqdot \dot{N}$ which uses the net change rate in daily Chinese tourist arrivals to be a proxy variable for the changes in daily returns on total Chinese tourist expenditures. Thus, we replace $r_{t}$ by $\dot{N}_{t}$ in equation (5), as follows:

$\dot{N}_{t}=E\left(r_{t} \mid I_{t-1}\right)+\varepsilon_{t}$ 
In order to capture a variety of long memory effects, we use the Heterogeneous Auto-Regressive (HAR) model as an alternative mean equation associated with the GARCH(1,1), GJR(1,1) and EGARCH(1,1) models to analyze the volatility in daily Chinese tourist arrivals to Taiwan.

The HAR model was proposed by Corsi (2009) to forecast realized volatilities. This method was inspired by the heterogeneous HARCH model of Müller et al. (1993) and Dacorogna et al. (1998), and by the asymmetric propagation of volatility between long and short time horizons. The heterogeneity of the model derives from the fact that different autoregressive structures are present at each time scale (for further details, see McAleer and Medeiros (2008)).

The HAR $(h)$ model is based on equation (7):

$\dot{N}_{t, h}=\frac{\dot{N}_{t}+\dot{N}_{t-1}+\dot{N}_{t-2}+\cdots+\dot{N}_{t-h+1}}{h}$

where the representative values of $h$ are one (for daily data), seven (for weekly data), and twenty-eight (for monthly data).

We use the $A R(1)$ process to measure the shock in the change rate of total Chinese tourists, $\varepsilon_{t}$, with daily $(h=1)$, weekly $(h=7)$, and monthly values ( $\left.h=28\right)$ for HAR, so the empirical model is given as follows:

$$
\begin{aligned}
& \dot{N}_{t}=\rho_{0}+\rho_{1} \dot{N}_{t-1}+\varepsilon_{t} \\
& \dot{N}_{t}=\rho_{0}+\rho_{1} \dot{N}_{t-1}+\rho_{2} \dot{N}_{t-1,7}+\varepsilon_{t}
\end{aligned}
$$


$\dot{N}_{t}=\rho_{0}+\rho_{1} \dot{N}_{t-1}+\rho_{2} \dot{N}_{t-1,7}+\rho_{3} \dot{N}_{t-1,28}+\varepsilon_{t}$

where equations (8)-(10) are referred to as the $\operatorname{HAR}(1), \operatorname{HAR}(1,7)$ and $\operatorname{HAR}(1,7,28)$ models, respectively.

\subsection{Random Coefficient Autoregressive Process and GARCH}

Given the mean equations (8)-(10), the random coefficient autoregressive process of $\varepsilon_{t}$ can be given as:

$\varepsilon_{t}=\phi_{t} \varepsilon_{t-1}+\eta_{t}$

where

$\phi_{t} \sim \operatorname{iid}(0, \alpha)$

$\eta_{t} \sim \operatorname{iid}(0, \omega)$

Tsay (1987) showed that the ARCH(1) model of Engle (1982) could be derived from the conditional expectation of the squared returns shocks in equation (11), and Bollerslev (1986) extended the ARCH(1) model to GARCH(1) model as equation (12):

$h_{t}=E\left(\varepsilon_{t-1}^{2} \mid I_{t-1}\right)=\omega+\alpha \varepsilon_{t-1}^{2}+\beta h_{t}$

where $h_{t}$ denotes conditional volatility, and $I_{t-1}$ is the information set at time $t-1$. 
As noted in McAleer (2014), at least one of $(\omega, \alpha, \beta)$ must be positive is a sufficient conditions for positivity of conditional volatility $h_{t}$ in equation (13), although these follow naturally from the regularity conditions underlying equation (11). From the specification of equation (11), $\alpha$ and $\omega$ are the variances of two different stochastic processes, and hence must be positive. The parameters in equation (12) are estimated by the maximum likelihood method to obtain Quasi-Maximum Likelihood Estimators (QMLE). The QMLE is efficient only if $\eta_{t}$ is normal, in which case it is the MLE.

When $\eta_{t}$ is not normal, adaptive estimation can be used to obtain efficient estimators, although this can be computationally intensive (see Ling and McAleer (2010)).

From equation (12), the ARCH (or $\alpha$ ) effect indicates the short run persistence of shocks, while the GARCH (or $\beta$ ) effect indicates the contribution of shocks to long run persistence (namely, $\alpha+\beta$ ). Moreover, as the GARCH process in equation (12) is a function of $\varepsilon_{t}$ (the unconditional shocks), the moments of $\varepsilon_{t}$ need to be investigated. Ling and McAleer (2003) showed that the QMLE for GARCH(p,q) is consistent if the second moment of $\varepsilon_{t}$ is finite. The well known necessary and sufficient condition for the existence of the second moment of $\varepsilon_{t}$ for GARCH(1,1) is $\alpha+\beta<1$

However, as the magnitude for positive and negative shocks are identical on conditional volatility in equation (12), the GARCH model only captures symmetric effects. And not asymmetry or leverage (see Black (1976) for further details).

\subsection{Random Coefficient Autoregressive Process and GJR}

The GJR model of Glosten et al. (1992) can be derived as a simple extension of the 
random coefficient autoregressive process in equation (7), with an indicator variable $I\left(\varepsilon_{t-1}\right)$ that is used to distinguish between the different effects of positive and negative returns shocks on subsequent volatility, namely:

$\varepsilon_{t}=\phi_{t} \varepsilon_{t-1}+\psi_{t} I\left(\varepsilon_{t-1}\right)+\eta_{t}$

where

$\phi_{t} \sim \operatorname{iid}(0, \alpha)$

$\eta_{t} \sim \operatorname{iid}(0, \omega)$

$\psi_{t} \sim \operatorname{iid}(0, \gamma)$

$I\left(\varepsilon_{t-1}\right)=1$ when $\varepsilon_{t-1}<0$

$I\left(\varepsilon_{t-1}\right)=0$ when $\varepsilon_{t-1} \geq 0$

The conditional expectation of the squared returns shocks in equation (10) can be shown to be an extension of equation (9), and is typically referred to as the GJR (or the threshold GARCH) model, as given below:

$h_{t}=E\left(\varepsilon_{t-1}^{2} \mid I_{t-1}\right)=\omega+\alpha \varepsilon_{t-1}^{2}+\gamma I\left(\varepsilon_{t-1}\right) \varepsilon_{t-1}^{2}+\beta h_{t-1}^{2}$

GJR is an asymmetric model and seeks to measure different effects for positive and negative shocks on conditional volatility. Asymmetry exists for GJR if:

Asymmetry for GJR: $\gamma>0$

It is clear that GARCH is nested within GJR, so that the interpretation of the 
coefficients in the two models is essentially the same, apart from the parameter associated with asymmetry. By analogy, at least one of $(\omega, \alpha, \gamma, \beta)$ must be positive for the positivity of conditional volatility $h_{t}$ in equation (14). It is obvious that $\alpha, \omega$, and $\gamma$ are the variances of three different stochastic processes, and hence must be positive.

The asymmetric effect, $\gamma$, measures the contribution of shocks to both short run persistence, $\alpha+\gamma / 2$, and to long run persistence, $\alpha+\beta+\gamma / 2$. Ling and McAleer (2003) showed that the regularity condition for the existence of the second moment for $\operatorname{GJR}(1,1)$ under symmetry of $\varepsilon_{t}$ is $\alpha+\beta+\gamma / 2<1$.

As shown in McAleer (2014), a special case of asymmetry is called leverage, which is the negative correlation between returns shocks and the subsequent shocks to volatility using the debt-equity ratio (see Black (1976)). The conditions for leverage in the GJR model in equation (14) are given as:

\section{Leverage for GJR: $\alpha<0$ and $\alpha+\gamma>0$}

As mentioned previously, $\alpha$ and $\gamma$ must be positive as they are variances in the random coefficient autoregressive process (13), so that leverage is not possible for the GJR model.

\subsection{Random Coefficient Complex Nonlinear Moving Average Process and EGARCH}

An alternative model that can accommodate asymmetry is the EGARCH model of 
Nelson (1990, 1991). McAleer and Hafner (2014) showed that EGARCH can be derived from a random coefficient complex nonlinear moving average (RCCNMA) process, as follows:

$\varepsilon_{t}=\phi_{t} \sqrt{\eta_{t-1}}+\psi_{t} I \sqrt{\eta_{t-1}}+\eta_{t}$

where

$\phi_{t} \sim \operatorname{iid}(0, \alpha)$

$\eta_{t} \sim \operatorname{iid}(0, \omega)$

$\psi_{t} \sim \operatorname{iid}(0, \gamma)$

$\sqrt{\eta_{t-1}}$ is a complex-valued function of $\eta_{t-1}$.

The conditional expectation of the squared returns shocks in equation (15) can be given as:

$h_{t}=E\left(\varepsilon_{t-1}^{2} \mid I_{t-1}\right)=\omega+\alpha\left|\eta_{-1}\right|+\gamma \eta_{-1}+\beta h_{t-1}$

Using the approximation $\log h_{t}=\log \left(1+\left(h_{t-1}-1\right)\right) \approx h_{t}-1$ to replace $h_{t}$ in equation (16), gives:

$\log h_{t}=\omega+\alpha\left|\eta_{t-1}\right|+\gamma \eta_{t-1}+\beta \log h_{t-1}, \quad|\beta|<1$

where the parameters $\alpha, \beta$ and $\gamma$ have different interpretations from those in the GARCH(1,1) and GJR(1,1) models. The parameters $\alpha$ and $\gamma$ in EGARCH(1,1) 
represent the size effect $(\alpha)$ and sign effect $(\gamma)$, respectively, of the standardized residuals, $\eta_{t}$, on the conditional variance.

EGARCH captures a different effect for positive and negative shocks on conditional volatility. Chang and McAleer (2017) derived the regularity conditions for asymmetry in EGARCH and provided the correct interpretation. Asymmetry exists for the EGARCH model if:

Asymmetry for EGARCH: $\alpha \neq 0$

McAleer and Hafner (2014) showed that the regularity conditions for leverage in the EGARCH model in equation (17) are:

\section{Leverage for EGARCH: $\gamma<0$ and $\gamma<\alpha<-\gamma$}

In virtually every empirical study where EGARCH is estimated, the QMLE of $\alpha$ is statistically significant, so $\alpha \neq 0$. Thus, in practice, EGARCH always displays asymmetry, though not leverage.

McAleer and Hafner (2014) and McAleer (2014) first demonstrated that leverage was not possible in the GJR and EGARCH models, as most previous empirical studies found leverage effects that were not being estimated and interpreted correctly. Moreover, as EGARCH is non-nested with both GARCH and GJR, the interpretation of the coefficients in EGARCH is not the same as in the other two conditional volatility models (McAleer, 2014). 
Unlike the GARCH model, EGARCH depends on lagged conditional shocks (or standardized residuals), so it does not require moment conditions to be established. Shephard (1996) observed that $|\beta|<1$ would likely be a sufficient condition for the existence of moments, consistency and asymptotic normality of the QMLE of EGARCH(1,1).

\section{Variables and Data}

The data comprise daily tourist arrivals from China to Taiwan for the period 1 January 2013 to 28 February 2018, giving 1,885 observations obtained from the National Immigration Agency of Taiwan. In this paper, three types of tourism, namely Group-type, Individual-type, and Medical-type, were used for purposes of comparison.

Seasonality is taken into account through the exponential smoothing process. Unlike the moving average model, which uses equal weights for smoothing, the exponential smoothing model assigns the highest weights to current observations and the smallest weights to the oldest observations. Exponential smoothing ensures that the time series display no strong or discernable seasonality or trend.

The formula for a single exponential smoothing is given in equation (18):

$$
\begin{aligned}
& N_{1}=A_{1} \\
& N_{t-} E S=w A_{t}+(1-w) N_{t-1}
\end{aligned}
$$

where $N_{t-} E S$ is the value of the exponentially smoothed series at time $t, A_{t}$ is the 
observed arrivals at time $t$, and $w$ is the subjectively assigned weight or smoothing coefficient, where $0<\mathrm{w}<1$.

Figure 1 presents the trends in overall tourism and three types of Chinese tourism. The first column shows trend without seasonal adjustment, and the second column shows trend with ES seasonal adjustment. As shown in Figure 1, Individual-type tourism shows a significant increase during the period of public holidays in China for every year, especially the Chinese Lunar New Year holidays (2013/2/9 2/15, 2014/1/31 2/6, 2015/2/18 2/24, 2016/2/7/ 2/13, 2017/1/27 2/2, 2018/2/15 2/21), and Chinese national holidays (10/1 10/7). Group-type tourism shows a significant decrease after May 2016 when Taiwan had the political party rotation and the presidential candidate of the Democratic Progressive Party (Ing-Wen Tsai) came the $14^{\text {th }}$ President of Taiwan.

However, as explained in Sections 3 and 4, we measure the change rate of tourists at time $t$ as follows:

$\dot{N}_{t}=100 *\left(\ln \left(N_{t}\right)-\ln \left(N_{t-1)}\right)\right)$

where $N_{t}$ and $N_{t-1}$ are the daily tourist arrivals at time periods $t$ and $t-1$, respectively.

Figure 2 shows the trends in the daily change rate of tourists. As shown in Figure 2, the first column shows trend without seasonal adjustment, and the second column shows trend with ES seasonal adjustment. The trend in Figure 2 is consistent with Figure 1, in which the Individual-type and Group-type tourism show bigger changes 
during the public holidays in China, especially at the end of September and early October in 2015 and 2016 for the Chinese national holidays. However, it seems that there is a volatility cluster effect for Medical-type tourism.

The definition of variables and descriptive statistics are given in Tables 1 and 2, respectively. All series exhibit significant leptokurtic behaviour, as evidenced by large kurtosis. All series show positive skewness that implies the series has a shorter left tail than right tail. The Jarque-Bera Lagrange multiplier test statistics indicate that none of these return series is normally distributed, which is not at all surprising for daily financial returns data, such as the change in the numbers of Chinese tourist arrivals.

The Augmented Dickey-Fuller (ADF) and Phillips-Perron (PP) unit root tests are used to check whether the series are stationary or not. Both unit root tests results are estimated using the econometric software package EViews 9.0, and are given in Table 3. As shown clearly in Table 3, there is no evidence of unit root in the daily change without seasonal adjustment $\left(\dot{N}_{t}\right)$, or in the daily change with exponentially smoothed adjustment $\left(\dot{N}_{t-} E S\right)$.

\section{Empirical Results}

Following the theoretical presentation in Section 4, Tables 4-7 report the empirical results with three conditional volatility models, GARCH $(1,1)$, GJR $(1,1)$ and EGARCH (1,1), respectively, for the change rate in All, Group-type, Individual-type and Medicine-type of Chinese tourists, respectively.

\subsection{Asymmetric Risk Effects for Changes in Chinese Tourists}


Table 4 reports the empirical results of the $\operatorname{GARCH}(1,1), \operatorname{GJR}(1,1)$, and EGARCH(1,1) conditional volatility models. The HAR model with no seasonal adjustment in the numbers of Chinese tourists will be shown in columns HAR(1), $\operatorname{HAR}(1,7)$, and $\operatorname{HAR}(1,7,28)$, respectively, and the results with seasonal adjustment for the numbers of Chinese tourists will be shown in column $E S$.

The QMLE of both the symmetric GARCH and asymmetric GJR are consistent and asymptotically normal as the second moment condition for GARCH model $(\alpha+\beta<1)$ and GJR model $(\alpha+\beta+\gamma / 2<1)$, respectively are satisfied for all series, with and without seasonal adjustment. However, as $|\beta|<1$ is satisfied for all series in the EGARCH(1,1) model, the QMLE would be a sufficient condition for the existence of moments, consistency and asymptotic normality.

In the upper part of Table 4, the mean equations show that the lagged dependent variables, $\rho_{1}$, are significantly less than one, with or without seasonal adjustment in the data series. These results are consistent with the unit root tests given in Table 3, which show no unit roots in the data for the change in the total numbers of Chinese tourists to Taiwan.

In the lower part of Table 4, the results for the GARCH(1,1) model show that a short run persistence in shocks $(\alpha)$ exists, as the QMLE of $\alpha$ is statistically significant at the $1 \%$ level in all series, whether with or without seasonal adjustment. According to the magnitude, the largest magnitude of $\alpha$ is $E S(0.208)$, followed by $\operatorname{HAR}(1)(0.197), \operatorname{HAR}(1,7)(0.193)$, and $\operatorname{HAR}(1,7,28)(0.187)$. 
The GARCH effect $(\beta)$ is also statistically significant at the $1 \%$ level for all series, whether with or without seasonal adjustment, which means the change rate in Chinese tourism affects the long run persistence of shocks. $E S(0.849)$ has the smallest effect of the long run persistence of shocks $(\alpha+\beta)$, while the magnitude of the long run persistence of shocks for $\operatorname{HAR}(1), \operatorname{HAR}(1,7), \operatorname{HAR}(1,7,28)$ are close to each other, at $0.874,0.876$ and 0.886 , respectively.

For the GJR(1,1) model, the ARCH shock $(\alpha)$ estimates are statistically significant at the 1\% level for all series. The QMLE of the asymmetric effect $(\gamma)$ is statistically significant for all series, except for $\operatorname{HAR}(1,7,28)$, so that $\operatorname{HAR}(1), \operatorname{HAR}(1,7)$, and $E S$ are all suitable for the asymmetric GJR model. The short run persistence of shocks $(\alpha+\gamma / 2)$ for the GJR model is slightly smaller than in GARCH $(\alpha)$, with or without seasonal adjustment. According to the magnitude of the run persistence of shocks, ES(0.205) shows the strongest effect, followed by $H A R(1)(0.199)$, $\operatorname{HAR}(1,7)(0.196$, and $\operatorname{HAR}(1,7,28)(0.163)$.

For the long-run persistence of shocks effect $(\alpha+\beta+\gamma / 2)$, the results are similar to their GARCH $(1,1)$ counterparts, with $E S(0.832)$ having the smallest long-run persistence of shocks effect, followed by $\operatorname{HAR}(1)(0.852), \operatorname{HAR}(1,7)(0.852)$, and $\operatorname{HAR}(1,7,28)(0.855)$

As described in Section 4, the parameters $\alpha$ and $\gamma$ represent the size and sign effects, respectively, of the standardized residuals on the conditional variance in the EGARCH $(1,1)$ model. The size effects $(\alpha)$ are significant and positive, and the sign effect $(\gamma)$ is significant and negative for all data series. For the magnitude of the size effects $(\alpha), \quad E S(0.392)$ is the largest, followed by 
$\operatorname{HAR}(1)(0.383), \operatorname{HAR}(1,7)(0.379), \operatorname{HAR}(1,7,28)(0.378)$. As $\quad \alpha \neq 0$ in the EGARCH $(1,1)$ model for $\operatorname{HAR}(1), \operatorname{HAR}(1,7), \operatorname{HAR}(1,7,28)$ and the $E S$ series, this finding means that risk exists as an asymmetric phenomenon.

\subsection{Risk Effects for Group-type Chinese Tourism}

Table 5 reports the empirical results of the $\operatorname{GARCH}(1,1), \operatorname{GJR}(1,1)$, and EGARCH(1,1) conditional volatility models for Group-type Chinese tourists. The QMLE in both the symmetric model GARCH and asymmetric model GJR are consistent and asymptotically normal as the second moment condition for GARCH $(\alpha+\beta<1)$ and GJR $(\alpha+\beta+\gamma / 2<1)$, respectively, are satisfied for all series with and without seasonal adjustment. However, as $|\beta|<1$ is satisfied for all series in the EGARCH(1,1) model, the QMLE would be a sufficient condition for the existence of moments, consistency and asymptotic normality.

In the upper part of Table 5, the mean equations show that the lagged dependent variables, $\rho_{1}$, are significantly less than one, with or without seasonal adjustment in all the data series. These results are consistent with the unit root tests given in Table 3, with no unit roots in the data for change in the total numbers of Group-type Chinese tourists.

In the lower part of Table 5, the results for the GARCH(1,1) model show that there is a short-run persistence of shocks effect $(\alpha)$, as the QMLE of $\alpha$ is statistically significant at the $1 \%$ level in all the series, with or without seasonal adjustment. According to the magnitude, the smallest magnitude of $\alpha$ is forES(0.097), followed by $\operatorname{HAR}(1,7,28)(0.110), \operatorname{HAR}(1)(0.120)$, and $\operatorname{HAR}(1,7)(0.193)$. 
The GARCH effect $(\beta)$ is also statistically significant at the $1 \%$ level in all series with or without seasonal adjustment, which means the change rate in the numbers of Chinese tourists displays a long run persistence effect in shocks. ES(0.937) has the largest long run persistence of shocks effect, $(\alpha+\beta)$, followed by $\operatorname{HAR}(1,7,28)(0.888), \operatorname{HAR}(1)(0.882)$, and $\operatorname{HAR}(1,7)(0.876)$, respectively.

For the GJR(1,1) model, the ARCH shock effect $(\alpha)$ is statistical insignificant for all series, while the asymmetric effect $(\gamma)$ is statistical significant at the $1 \%$ level for all series. Thus, the short run persistence of shocks $(\alpha+\gamma / 2)$ for the GJR model is smaller than for GARCH $(\alpha)$, with or without seasonal adjustment. $H A R(1)(0.098)$ and $\operatorname{HAR}(1,7)(0.098)$ have equal magnitudes for the run persistent of shocks effect, followed by $\operatorname{HAR}(1,7,28)(0.090)$ and $E S(0.090)$.

For the long-run persistence of shocks effect $(\alpha+\beta+\gamma / 2)$, the results are similar to their GARCH $(1,1)$ counterparts, where $E S(0.949)$ has the largest long-run persistence of shocks effect, followed by $H A R(1)(0.926), H A R(1,7)(0.919)$, and $\operatorname{HAR}(1,7,28)(0.914)$.

For the EGARCH $(1,1)$ model, the size effects $(\alpha)$ are statistically significant at the $1 \%$ level in all series, with or without seasonal adjustment. $H A R(1,7)(0.180)$ and $\operatorname{HAR}(1,7,28)(0.180)$ have equal size effects, followed by $\operatorname{HAR}(1)(0.173)$ and $E S(0.172)$. Moreover, the sign effect $(\gamma)$ is found to be negative and significant at the 1\% level in all series, whether with or without seasonal adjustment.

\subsection{Risk Effects for the Individual-type Chinese Tourists}


Table 6 reports the empirical results of the $\operatorname{GARCH}(1,1), \operatorname{GJR}(1,1)$, and EGARCH(1,1) conditional volatility models for Individual-type Chinese tourists. The QMLE of both the symmetric model GARCH and asymmetric model GJR are consistent and asymptotically normal as the second moment condition for the GARCH model, $(\alpha+\beta<1)$, and GJR model $(\alpha+\beta+\gamma / 2<1)$, respectively, are satisfied for all series, with and without seasonal adjustment. However, as $|\beta|<1$ is satisfied for all series for the EGARCH(1,1) model, the QMLE would be a sufficient condition for the existence of moments, consistency and asymptotic normality.

In the upper part of Table 6, the mean equations show that the coefficient of the lagged dependent variables, $\rho_{1}$, are significantly less than one, with or without seasonal adjustment in all data series. These results are consistent with the unit root tests given in Table 3, which show no unit roots in the data for the change in the total numbers of Individual-type Chinese tourists.

In the lower part of Table 6, the results for the GARCH(1,1) model show that there is a short run persistence of shocks effect $(\alpha)$, as the QMLE of $\alpha$ is statistically significant at the $1 \%$ level in all series, with or without seasonal adjustment. According to the magnitude, the largest magnitude of $\alpha$ is $H A R(1)(0.285)$, followed by $\operatorname{ES}(0.28), \operatorname{HAR}(1,7)(0.274)$ and $\operatorname{HAR}(1,7,28)(0.267)$.

The GARCH effect $(\beta)$ is also statistically significant at the $1 \%$ level in all series, with or without seasonal adjustment, which means the change rate in Chinese tourism has a long run persistence of shocks effect. $\operatorname{HAR}(1,7,28)(0.809)$ has the largest long run persistence of shocks effect $(\alpha+\beta)$, followed by $\operatorname{HAR}(1,7)(0.805), E S(0.802)$, 
and $\operatorname{HAR}(1)(0.799)$, respectively.

For the GJR(1,1) model, the ARCH shock $(\alpha)$ is statistically significant at the $1 \%$ level for all series. The asymmetric effect $(\gamma)$ is negative and significant for $\operatorname{HAR}(1,7)$ and $\operatorname{HAR}(1,7,28)$, but insignificant for $\operatorname{HAR}(1)$ and $E S$. Therefore, the shock effect for short run and long run persistence are symmetric for Individual-type Chinese tourism.

For the EGARCH $(1,1)$ model, the size effects $(\alpha)$ are statistically significant at the $1 \%$ level in all series, with or without seasonal adjustment. $H A R(1)(0.460)$ has the largest size effect, followed by $E S(0.459), H A R(1,7)(0.440)$, and $\operatorname{HAR}(1,7,28)(0.436)$. However, the sign effect $(\gamma)$ is found to be insignificant for all series, with or without seasonal adjustment, except for the $\operatorname{HAR}(1,7)$ and $\operatorname{HAR}(1,7,28)$ models.

\subsection{Risk Effects for the Medical-type Chinese Tourists}

Table 7 reports the empirical results of the $\operatorname{GARCH}(1,1), \operatorname{GJR}(1,1)$, and EGARCH(1,1) conditional volatility models for Medical-type Chinese tourism. The QMLE of the symmetric model GARCH is consistent and asymptotically normal as the second moment condition for GARCH model $(\alpha+\beta<1)$ is satisfied for all series. The QMLE of the asymmetric model GJR is consistent and asymptotically normal as the second moment condition for GJR, $(\alpha+\beta+\gamma / 2<1)$, is only satisfied for the HAR series, but ES series. However, as $|\beta|<1$ are satisfied for all series in EGARCH(1,1) model, the QMLE would be a sufficient condition for the existence of moments, consistency and asymptotic normality. In the following 
discussion, we report the $H A R$ empirical results only for GJR model.

In the upper part of Table 7, the mean equations show that the lagged dependent variables, $\rho_{1}$, are significantly less than one, with or without seasonal adjustment, in all the data series. These results are consistent with the unit root tests given in Table 3, with no unit roots in the change in the total numbers of Medical-type Chinese tourists.

In the lower part of Table 7, the results for the GARCH(1,1) model show that there is a short run persistence of shocks effect $(\alpha)$, as $\alpha$ is statistically significant at the $1 \%$ level in all series, with or without seasonal adjustment. According to the magnitude, the largest magnitude of $\alpha$ is $\operatorname{HAR}(1)(0.053)$, followed by $\operatorname{HAR}(1,7,28)(0.048)$, $\operatorname{HAR}(1,7)(0.045)$, and $E S(0.014)$.

The GARCH effect $(\beta)$ is also statistically significant at the $1 \%$ level in all series, with or without seasonal adjustment, which means the change rate in Chinese tourists exhibit long run persistence of shocks effects. ES(0.992) has the largest long run persistence of shocks effect $(\alpha+\beta)$, while the magnitude of long run persistence of shocks effect for $\operatorname{HAR}(1), \operatorname{HAR}(1,7), \operatorname{HAR}(1,7,28)$ are close to each other, at 0.977, 0.978 and 0.976, respectively.

For the GJR(1,1) model, the QMLE of the ARCH shock $(\alpha)$ is insignificant for the $\operatorname{HAR}(1), \operatorname{HAR}(1,7), \operatorname{HAR}(1,7,28)$ series, while the asymmetric effect $(\gamma)$ is statistically significant at the $1 \%$ level in all series without seasonal adjustments.

For the long-run persistence of shocks effect, $(\alpha+\beta+\gamma / 2)$, the results are similar to their GARCH $(1,1)$ counterparts, with $\operatorname{HAR}(1,7)(0.994)$ having the largest long run 
persistence of shocks effect, followed by $\operatorname{HAR}(1,7,28)(0.992)$, and $H A R(1)(0.977)$.

For the EGARCH(1,1) model, the QMLE of the size effects $(\alpha)$ is statistically significant in all series, with or without seasonal adjustment, except for ES . $\operatorname{HAR}(1,7,28)(0.061)$ has the largest estimated size effect $(\alpha)$, followed by $\operatorname{HAR}(1,7)(0.032)$ and $\operatorname{HAR}(1)(0.023)$. The sign effect $(\gamma)$ is found to be negative and significant for all series, with or without seasonal adjustment. Somewhat unusually, a leverage effect is found for EGARCH $(\gamma<0$ and $\gamma<\alpha<-\gamma)$, in all series with or without seasonal adjustment, for the Medical-type Chinese Tourism.

\section{Concluding Remarks}

By the end of 2016 , with $37.64 \%$ of the total number of international tourists to Taiwan, China had become Taiwan's largest source of international tourism. However, the numbers of Chinese tourists coming to Taiwan have been very closely related to the political relationship across the Taiwan Strait. Thus, the purpose of this paper was to investigate the short run and long run persistence of shocks in the change rate of Chinese tourists of various kinds to Taiwan by using daily data from 1 January 2013 to 28 February 2018.

Using McAleer's (2015) fundamental equation in tourism finance, and linking the change rate in tourism and change in tourism revenue, this paper applied three widely-used univariate conditional volatility models, namely GARCH(1,1), GJR(1,1), and EGARCH(1,1), to measure the short and long run persistence of shocks in the volatility of the change of Chinese tourists in Taiwan, as well as to examine the 
symmetric and asymmetric effects in the volatility of three alternative types of Chinese tourissm to Taiwan.

In order to capture a variety of long memory effects, we use three different Heterogeneous Auto-Regressive (HAR) models, namely $\operatorname{HAR}(1), \operatorname{HAR}(1,7)$, and $\operatorname{HAR}(1,7,28)$, as alternative mean equations associated with the $\operatorname{GARCH}(1,1)$, GJR(1,1), and EGARCH(1,1) conditional volatility models. We also use the exponential smoothing process, $N_{t-} E S$, instead of HAR, to measure the shocks in the change rate of total Chinese tourists, $\varepsilon_{t}$, in order to reduce the possible influence of seasonality in the time series.

The empirical results show asymmetric impacts of positive and negative shocks on the volatility of changes in the numbers of Group-type and Medical-type tourism. However, the asymmetric impacts were not found in Individual-type Chinese tourism These empirical results suggest that Taiwan tourism authorities should act to prevent the negative shocks for Group-type and Medical-type Chinese tourism to dampen the shocks that might arise from fewer Chinese tourists in the future.

Individual-type Chinese tourism shows a symmetric volatility pattern, where positive and negative shocks have the same magnitude effects on the volatility of changes in the numbers of tourist arrivals.

Somewhat unusually, there exists a leverage effects for EGARCH in the sub-sample of Medical-type Chinese tourism, which shows a negative correlation between shocks in daily tourist arrivals and subsequent shocks to volatility 
For the asymmetric magnitude effect for both Group-type and Medical-type Chinese tourism, the negative shocks have shown a larger impact on volatility than do positive shocks. However, there exists a leverage effect for the Medical-type tourism, so a small shock would increase the volatility in the change in the numbers of Medical-type tourism, while a big shock would decrease volatility in the change in the numbers of Medical-type tourism.

This paper shows negative shocks have little impact on the numbers of Medical-type and Individual-type Chinese tourism to Taiwan. On the contrary, Group-type Chinese tourism has been shown to have a significant impact by Taiwan President Tsai Ing-wen, who cannot satisfy the China government's Cross-Strait policy (negative shocks). Therefore, the Taiwan government should develop appropriate strategies when the tourism industry is affected by negative shocks, or downturns in Group-type tourism to Taiwan.

This paper is designed to investigate the impact of changes in the numbers of various kinds of Chinese tourists to Taiwan. The empirical findings in can serve as a useful reference to the Taiwan Government for its policy-making regarding international tourism in the future. 
Figure 1

Daily Number of Chinese Tourists from 1 January 2013 to 28 February 2018

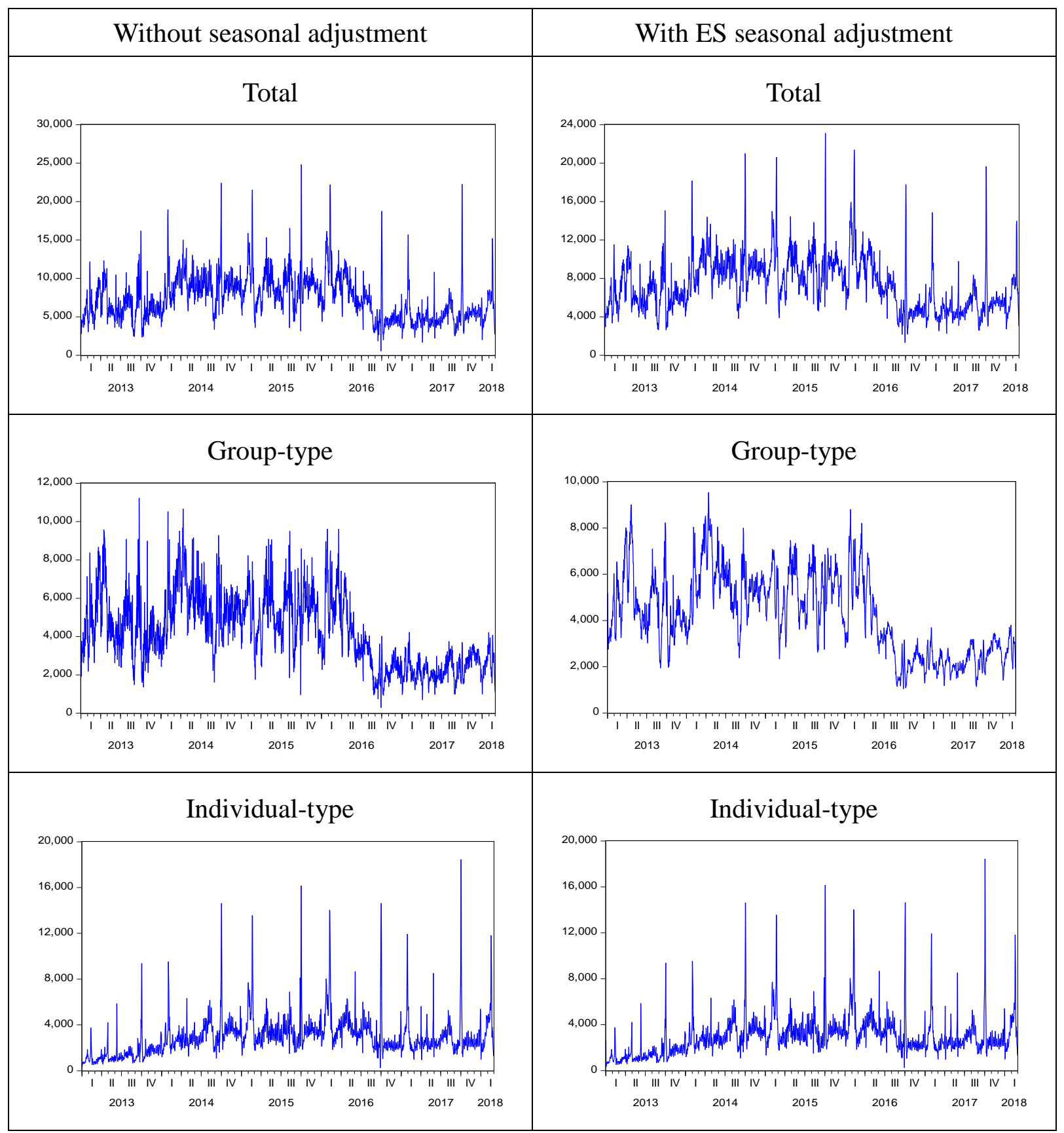




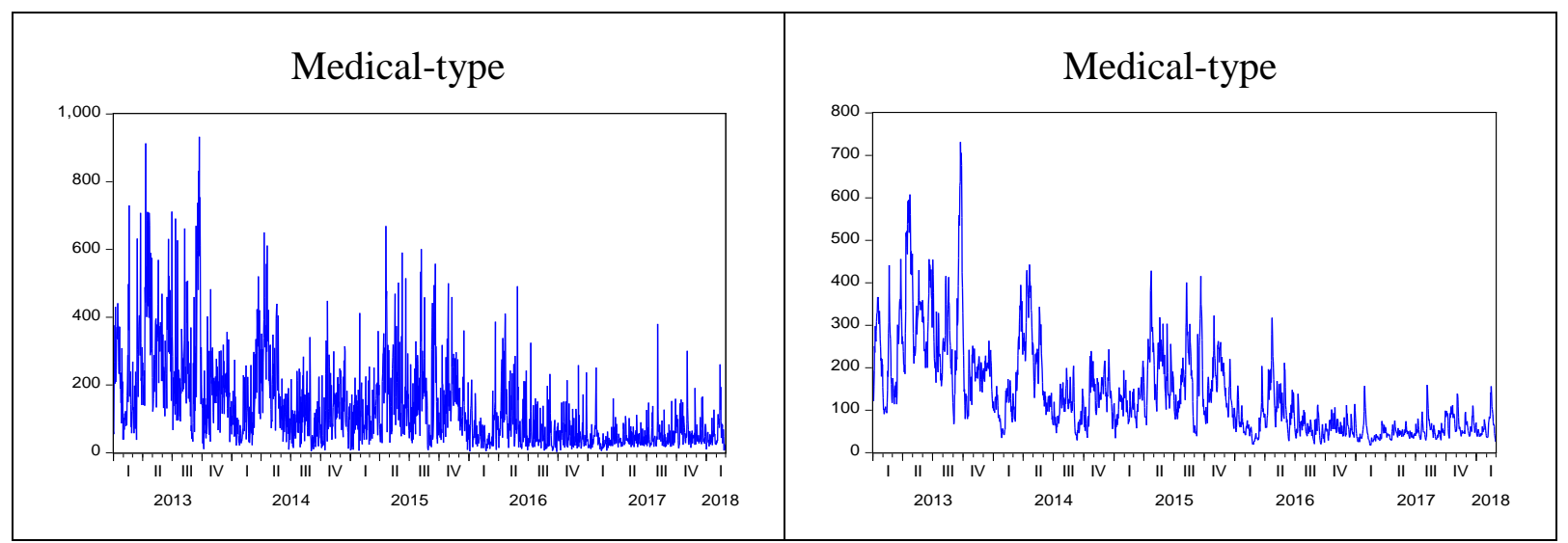

Figure 2

Daily Change Rate of Chinese Tourists from 1 January 2013 to 28 February 2018.

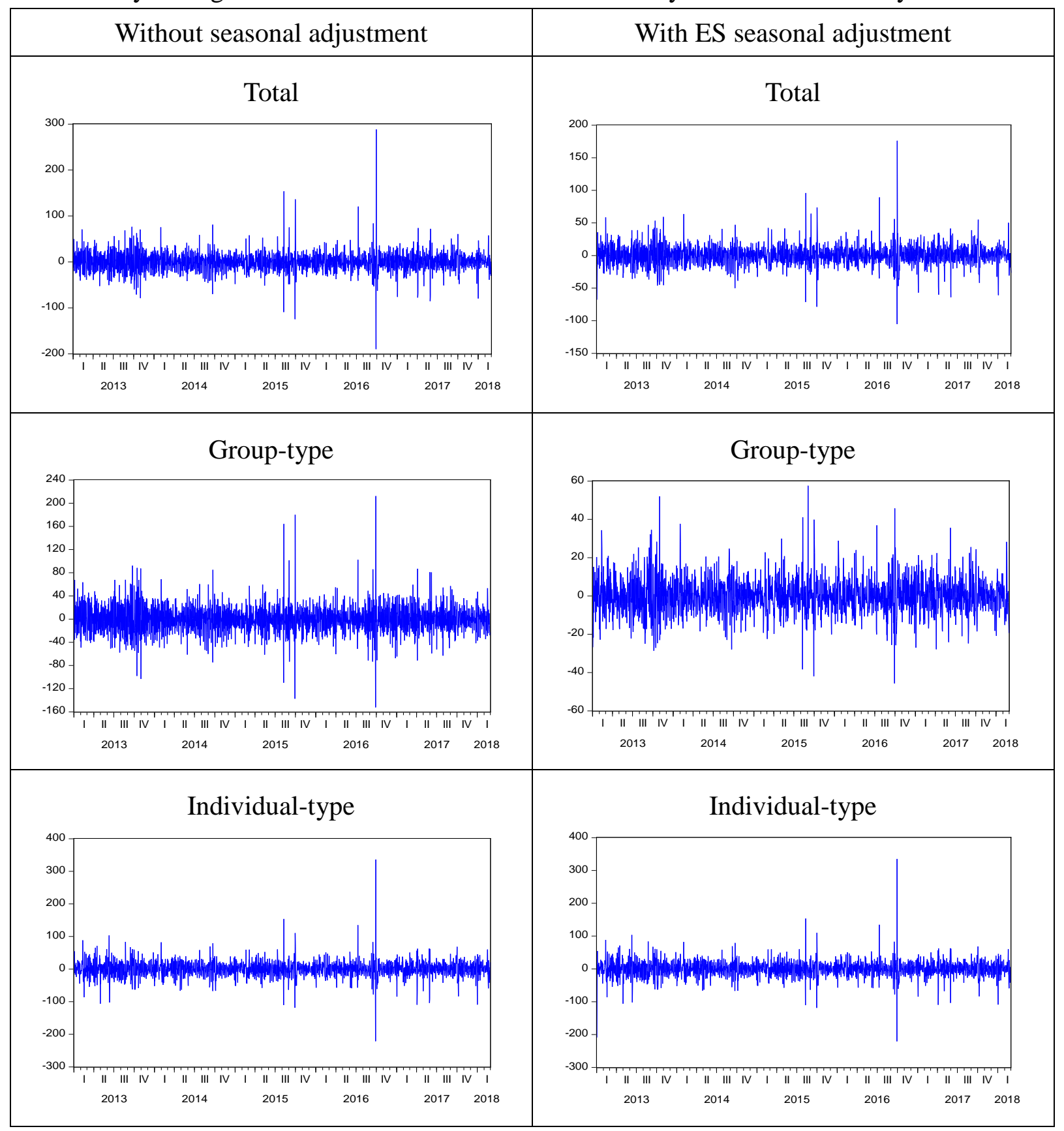




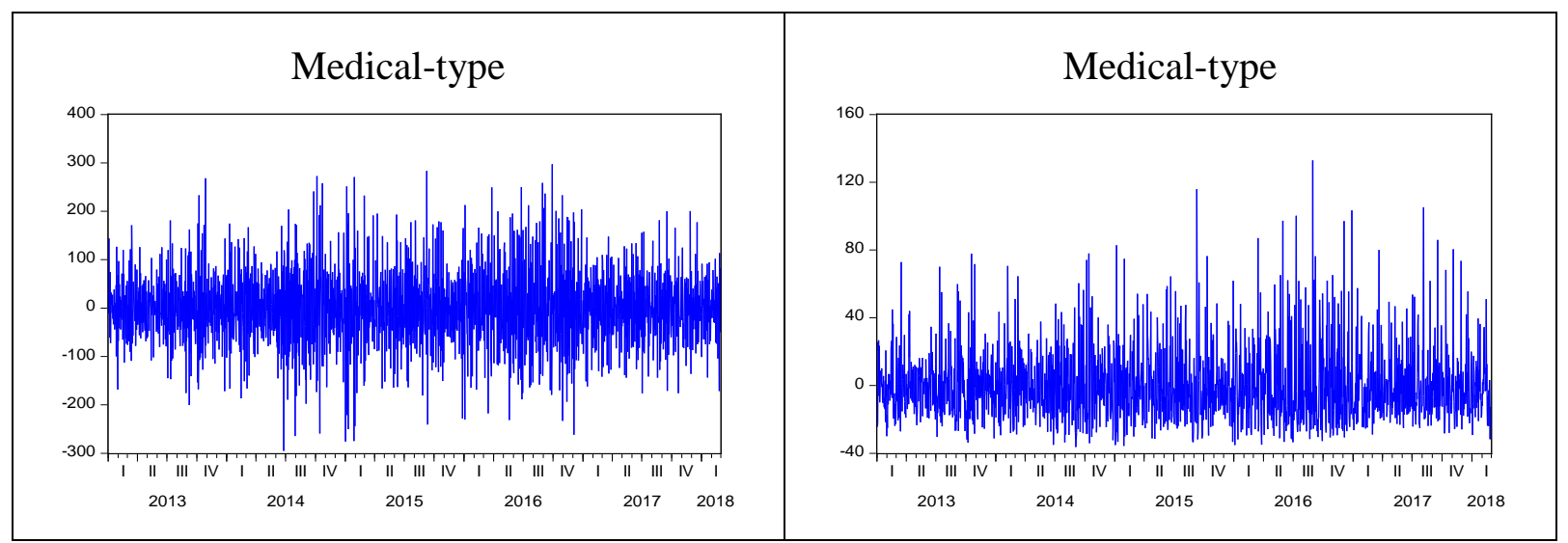

Table 1

Definitions of Variables

\begin{tabular}{|c|c|}
\hline Variables & Definition \\
\hline$N_{t}$ & Number of Chinese tourists at day $t$. \\
\hline \multirow{2}{*}{$N_{t \_} E S$} & Number of Chinese tourists with the exponential smoothing (ES) \\
\hline & seasonal adjustment at day $t$. \\
\hline$\dot{N}_{t}$ & The change rate of number of Chinese tourists. \\
\hline$\dot{N}_{t-} E S$ & $\begin{array}{l}\text { The change rate of number of Chinese tourists with ES seasonal } \\
\text { adjustment. }\end{array}$ \\
\hline
\end{tabular}


Table 2

Descriptive Statistics

\begin{tabular}{|c|c|c|c|c|}
\hline & \multicolumn{4}{|c|}{$\dot{N}_{t}$ (no seasonal adjustment) } \\
\hline & Total & Group-type & Individual-type & Medical-type \\
\hline Mean & -0.001 & -0.041 & 0.085 & -0.048 \\
\hline Median & -0.704 & -0.878 & -0.087 & -2.354 \\
\hline Maximum & 288.299 & 212.195 & 336.128 & 297.041 \\
\hline Minimum & -189.843 & -152.377 & -221.329 & -294.969 \\
\hline Std. Dev. & 22.751 & 25.186 & 25.796 & 80.943 \\
\hline Skewness & 1.007 & 0.523 & 0.789 & 0.142 \\
\hline Kurtosis & 21.980 & 9.500 & 23.063 & 3.769 \\
\hline Jarque-Bera & 28597.630 & 3403.152 & 31794.670 & 52.809 \\
\hline Probability & 0.000 & 0.000 & 0.000 & 0.000 \\
\hline \multirow[t]{3}{*}{ No. observations } & 1884 & 1884 & 1884 & 1884 \\
\hline & \multicolumn{4}{|c|}{$\dot{N}_{t-} E S$ (with ES seasonal adjustment) } \\
\hline & Total & Group-type & Individual-type & Medical-type \\
\hline Mean & -0.052 & -0.053 & -0.037 & -0.108 \\
\hline Median & -0.241 & -0.341 & -0.096 & -3.623 \\
\hline Maximum & 175.811 & 57.636 & 335.220 & 132.870 \\
\hline Minimum & -105.419 & -45.605 & -220.521 & -36.316 \\
\hline Std. Dev. & 16.214 & 9.720 & 26.202 & 21.404 \\
\hline Skewness & 0.688 & 0.403 & 0.491 & 1.428 \\
\hline Kurtosis & 13.493 & 5.367 & 23.612 & 6.340 \\
\hline Jarque-Bera & 8791.883 & 490.742 & 33427.420 & 1515.462 \\
\hline Probability & 0.000 & 0.000 & 0.000 & 0.000 \\
\hline No. observations & 1884 & 1884 & 1884 & 1884 \\
\hline
\end{tabular}


Table 3

Unit Root Tests for Daily Change Rate of Chinese Tourists

\begin{tabular}{|c|c|c|c|c|c|c|}
\hline \multirow[b]{2}{*}{ Variable } & \multicolumn{3}{|c|}{ ADF (t-ratio) } & \multicolumn{3}{|c|}{ PP (t-ratio) } \\
\hline & $\begin{array}{l}\text { Constant } \\
\text { and trend }\end{array}$ & Constant & None & $\begin{array}{l}\text { Constant } \\
\text { and trend }\end{array}$ & Constant & None \\
\hline \multicolumn{7}{|c|}{ Total } \\
\hline$\dot{N}_{t}$ & $-11.942 *$ & $-11.938 *$ & $-11.943^{*}$ & $-73.708^{*}$ & $-73.691 *$ & $-73.717 *$ \\
\hline$\dot{N}_{t_{-}} E S$ & $-12.827^{*}$ & $-12.826^{*}$ & $-12.831^{*}$ & $-52.318^{*}$ & $-52.321^{*}$ & $-52.341 *$ \\
\hline \multicolumn{7}{|c|}{ Group-type } \\
\hline$\dot{N}_{t}$ & $-12.867^{*}$ & $-12.861^{*}$ & $-12.862 *$ & $-89.494 *$ & $-89.473^{*}$ & $-89.500 *$ \\
\hline$\dot{N}_{t_{-}} E S$ & $-13.794^{*}$ & $-13.791^{*}$ & $-13.792^{*}$ & $-40.908^{*}$ & $-40.918^{*}$ & $-40.930 *$ \\
\hline \multicolumn{7}{|c|}{ Individual-type } \\
\hline$\dot{N}_{t}$ & $-12.222^{*}$ & $-12.215^{*}$ & $-12.216^{*}$ & $-65.874 *$ & $-651.817^{*}$ & $-65.820 *$ \\
\hline$\dot{N}_{t_{-}} E S$ & $-12.240^{*}$ & $-12.232 *$ & $-12.231^{*}$ & $-67.641^{*}$ & $-66.189 *$ & $-66.195 *$ \\
\hline \multicolumn{7}{|c|}{ Medical-type } \\
\hline$\dot{N}_{t}$ & $-25.446^{*}$ & $-25.453^{*}$ & $-25.458 *$ & $-234.288 *$ & $-234.634 *$ & $-234.304^{*}$ \\
\hline$\dot{N}_{t_{-}} E S$ & $-22.997 *$ & $-23.003^{*}$ & $-23.007 *$ & $-52.541 *$ & $-52.580 *$ & $-52.569 *$ \\
\hline
\end{tabular}

Note: * denotes significance at the $1 \%$ level. 
Table 4: Conditional Volatility Models for the Daily Change Rate of the Number of All Chinese Tourists

\begin{tabular}{|c|c|c|c|c|c|c|c|c|c|c|c|c|}
\hline \multirow{2}{*}{ Model } & \multicolumn{4}{|c|}{ GARCH(1,1) } & \multicolumn{4}{|c|}{$\operatorname{GJR}(\mathbf{1}, \mathbf{1})$} & \multicolumn{4}{|c|}{ EGARCH(1,1) } \\
\hline & $\operatorname{HAR}(1)$ & $\operatorname{HAR}(1,7)$ & $\operatorname{HAR}(1,7,28)$ & ES & $\operatorname{HAR}(1)$ & $\operatorname{HAR}(1,7)$ & $\operatorname{HAR}(1,7,28)$ & ES & $\operatorname{HAR}(1)$ & $\operatorname{HAR}(1,7)$ & $\operatorname{HAR}(1,7,28)$ & ES \\
\hline Coefficient & \multicolumn{4}{|c|}{ Mean } & \multicolumn{4}{|c|}{ Mean } & \multicolumn{4}{|c|}{ Mean } \\
\hline$\rho_{0}$ & $\begin{array}{c}0.175 \\
(0.422)\end{array}$ & $\begin{array}{c}0.167 \\
(0.399)\end{array}$ & $\begin{array}{c}-0.012 \\
(-0.029)\end{array}$ & $\begin{array}{c}0.309 \\
(1.004)\end{array}$ & $\begin{array}{c}-0.066 \\
(-0.146)\end{array}$ & $\begin{array}{c}-0.060 \\
(-0.130)\end{array}$ & $\begin{array}{c}-0.155 \\
(-0.341)\end{array}$ & $\begin{array}{c}0.059 \\
(0.175)\end{array}$ & $\begin{array}{c}-0.110 \\
(-0.255)\end{array}$ & $\begin{array}{c}-0.122 \\
(-0.278)\end{array}$ & $\begin{array}{c}-0.017 \\
(-0.039)\end{array}$ & $\begin{array}{c}0.037 \\
(0.115)\end{array}$ \\
\hline$\rho_{1}$ & $\begin{array}{l}-0.303^{* *} \\
(-11.748)\end{array}$ & $\begin{array}{l}-0.295^{* *} \\
(-10.845)\end{array}$ & $\begin{array}{l}-0.289 * * \\
(-10.591)\end{array}$ & $\begin{array}{c}-0.106 * * \\
(-4.038)\end{array}$ & $\begin{array}{l}-0.295^{* *} \\
(-11.402)\end{array}$ & $\begin{array}{l}-0.288 * * \\
(-10.503)\end{array}$ & $\begin{array}{l}-0.285^{* *} \\
(-10.339)\end{array}$ & $\begin{array}{c}-0.095^{* *} \\
(-3.631)\end{array}$ & $\begin{array}{l}-0.285^{* *} \\
(-11.540)\end{array}$ & $\begin{array}{l}-0.279 * * \\
(-10.772)\end{array}$ & $\begin{array}{l}-0.275^{* *} \\
(-10.448)\end{array}$ & $\begin{array}{c}-0.087 * * \\
(-3.470)\end{array}$ \\
\hline$\rho_{2}$ & - & $\begin{array}{c}-0.104 \\
(-0.948)\end{array}$ & $\begin{array}{c}-0.001 \\
(-0.010)\end{array}$ & - & - & $\begin{array}{c}-0.099 \\
(-0.941)\end{array}$ & $\begin{array}{c}-0.002 \\
(-0.015)\end{array}$ & - & - & $\begin{array}{c}-0.100 \\
(-1.044)\end{array}$ & $\begin{array}{c}0.002 \\
(0.021)\end{array}$ & - \\
\hline$\rho_{3}$ & - & - & $\begin{array}{l}-1.065^{* *} \\
(-4.305)\end{array}$ & - & - & - & $\begin{array}{c}-1.019 * * \\
(-3.999)\end{array}$ & - & - & - & $\begin{array}{c}-0.904^{* *} \\
(-3.339)\end{array}$ & - \\
\hline Coefficient & \multicolumn{4}{|c|}{ Variance } & \multicolumn{4}{|c|}{ Variance } & \multicolumn{4}{|c|}{ Variance } \\
\hline$\omega$ & $\begin{array}{c}61.986 * * \\
(10.216)\end{array}$ & $\begin{array}{c}60.962 * * \\
(9.721)\end{array}$ & $\begin{array}{c}55.853 * * \\
(9.711)\end{array}$ & $\begin{array}{c}39.322^{* *} \\
(7.526)\end{array}$ & $\begin{array}{c}70.846^{* *} \\
(7.724)\end{array}$ & $\begin{array}{c}70.815^{* *} \\
(7.578)\end{array}$ & $\begin{array}{c}59.121^{* *} \\
(8.197)\end{array}$ & $\begin{array}{c}43.092 * * \\
(6.910)\end{array}$ & $\begin{array}{c}0.841 * * \\
(5.430)\end{array}$ & $\begin{array}{c}0.852 * * \\
(5.393)\end{array}$ & $\begin{array}{c}0.780 * * \\
(5.385)\end{array}$ & $\begin{array}{c}0.721^{* *} \\
(5.181)\end{array}$ \\
\hline$\alpha$ & $\begin{array}{c}0.197 * * \\
(9.844)\end{array}$ & $\begin{array}{c}0.193 * * \\
(9.618)\end{array}$ & $\begin{array}{c}0.187 * * \\
(9.868)\end{array}$ & $\begin{array}{c}0.208 * * \\
(9.988)\end{array}$ & $\begin{array}{c}0.156 * * \\
(5.862)\end{array}$ & $\begin{array}{c}0.154 * * \\
(5.561)\end{array}$ & $\begin{array}{c}0.163 * * \\
(6.241)\end{array}$ & $\begin{array}{c}0.149 * * \\
(5.481)\end{array}$ & $\begin{array}{l}0.383^{* *} \\
(12.139)\end{array}$ & $\begin{array}{l}0.379 * * \\
(11.812)\end{array}$ & $\begin{array}{l}0.378 * * \\
(12.561)\end{array}$ & $\begin{array}{c}0.392 * * \\
(13.375)\end{array}$ \\
\hline$\gamma$ & - & - & - & - & $\begin{array}{l}0.085^{*} \\
(2.343)\end{array}$ & $\begin{array}{l}0.083^{*} \\
(2.234)\end{array}$ & $\begin{array}{c}0.046 \\
(1.352)\end{array}$ & $\begin{array}{c}0.111^{* *} \\
(3.197)\end{array}$ & $\begin{array}{l}-0.060 * * \\
(-3.542)\end{array}$ & $\begin{array}{l}-0.060 * * \\
(-3.370)\end{array}$ & $\begin{array}{l}-0.043^{*} \\
(-2.469)\end{array}$ & $\begin{array}{c}-0.066^{* *} \\
(-3.734)\end{array}$ \\
\hline$\beta$ & $\begin{array}{l}0.677 * * \\
(36.343)\end{array}$ & $\begin{array}{l}0.683 * * \\
(33.207)\end{array}$ & $\begin{array}{l}0.699 * * \\
(39.611)\end{array}$ & $\begin{array}{l}0.641 * * \\
(21.386)\end{array}$ & $\begin{array}{l}0.653 * * \\
(23.450)\end{array}$ & $\begin{array}{l}0.656 * * \\
(22.290)\end{array}$ & $\begin{array}{l}0.692 * * \\
(32.666)\end{array}$ & $\begin{array}{l}0.627 * * \\
(17.385)\end{array}$ & $\begin{array}{l}0.811^{* *} \\
(30.574)\end{array}$ & $\begin{array}{l}0.810 * * \\
(29.839)\end{array}$ & $\begin{array}{l}0.822 * * \\
(33.518)\end{array}$ & $\begin{array}{l}0.811^{* *} \\
(30.518)\end{array}$ \\
\hline Second moment & 0.874 & 0.876 & 0.886 & 0.849 & 0.852 & 0.852 & 0.855 & 0.832 & - & - & - & - \\
\hline
\end{tabular}

Notes: t-values are in parentheses; * and ** indicate significance at the $5 \%$ and $1 \%$ levels, respectively; $\alpha+\beta<1$ is the second moment condition for $\operatorname{GARCH}(1,1) ; \alpha+\beta+\frac{\gamma}{2}<1$ is the second moment condition for $\operatorname{GJR}(1,1)$. 
Table 5: Conditional Volatility Models for the Daily Change Rate of the Number of Group-type Chinese Tourists

\begin{tabular}{|c|c|c|c|c|c|c|c|c|c|c|c|c|}
\hline \multirow{2}{*}{ Model } & \multicolumn{4}{|c|}{ GARCH(1,1) } & \multicolumn{4}{|c|}{ GJR(1,1) } & \multicolumn{4}{|c|}{ EGARCH(1,1) } \\
\hline & $\operatorname{HAR}(1)$ & $\operatorname{HAR}(1,7)$ & $\operatorname{HAR}(1,7,28)$ & ES & $\operatorname{HAR}(1)$ & $\operatorname{HAR}(1,7)$ & $\operatorname{HAR}(1,7,28)$ & ES & $\operatorname{HAR}(1)$ & $\operatorname{HAR}(1,7)$ & $\operatorname{HAR}(1,7,28)$ & ES \\
\hline Coefficient & \multicolumn{4}{|c|}{ Mean } & \multicolumn{4}{|c|}{ Mean } & \multicolumn{4}{|c|}{ Mean } \\
\hline$\rho_{0}$ & $\begin{array}{c}0.001 \\
(0.002)\end{array}$ & $\begin{array}{c}0.167 \\
(0.399)\end{array}$ & $\begin{array}{c}-0.107 \\
(-0.215)\end{array}$ & $\begin{array}{c}0.157 \\
(0.748)\end{array}$ & $\begin{array}{l}-1.073 * \\
(-2.184)\end{array}$ & $\begin{array}{l}-1.018 * \\
(-2.065)\end{array}$ & $\begin{array}{l}-0.983 * \\
(-1.989)\end{array}$ & $\begin{array}{c}-0.251 \\
(-1.220)\end{array}$ & $\begin{array}{c}-1.497 * * \\
(-3.053)\end{array}$ & $\begin{array}{c}-1.399 * * \\
(-2.828)\end{array}$ & $\begin{array}{l}-1.302 * * \\
(-2.629)\end{array}$ & $\begin{array}{c}-0.319 \\
(-1.549)\end{array}$ \\
\hline$\rho_{1}$ & $\begin{array}{l}-0.412^{* *} \\
(-17.580)\end{array}$ & $\begin{array}{l}-0.295^{* *} \\
(-10.845)\end{array}$ & $\begin{array}{l}-0.395^{* *} \\
(-15.760)\end{array}$ & $\begin{array}{c}0.032 \\
(1.313)\end{array}$ & $\begin{array}{l}-0.403 * * \\
(-18.892)\end{array}$ & $\begin{array}{l}-0.395^{* *} \\
(-16.757)\end{array}$ & $\begin{array}{l}-0.388 * * \\
(-16.312)\end{array}$ & $\begin{array}{c}0.034 \\
(1.466)\end{array}$ & $\begin{array}{l}-0.392 * * \\
(-19.075)\end{array}$ & $\begin{array}{l}-0.383 * * \\
(-16.491)\end{array}$ & $\begin{array}{l}-0.379 * * \\
(-15.928)\end{array}$ & $\begin{array}{l}0.044^{*} \\
(2.030)\end{array}$ \\
\hline$\rho_{2}$ & - & $\begin{array}{c}-0.104 \\
(-0.948)\end{array}$ & $\begin{array}{c}0.035 \\
(0.266)\end{array}$ & - & - & $\begin{array}{c}-0.135 \\
(-1.293)\end{array}$ & $\begin{array}{c}0.010 \\
(0.086)\end{array}$ & - & - & $\begin{array}{c}-0.146 \\
(-1.361)\end{array}$ & $\begin{array}{c}-0.051 \\
(-0.460)\end{array}$ & - \\
\hline$\rho_{3}$ & - & - & $\begin{array}{l}-1.773 * * \\
(-4.584)\end{array}$ & - & - & - & $\begin{array}{c}-1.409 * * \\
(-4.011)\end{array}$ & - & - & - & $\begin{array}{c}-1.137 * * \\
(-3.517)\end{array}$ & - \\
\hline Coefficient & \multicolumn{4}{|c|}{ Variance } & \multicolumn{4}{|c|}{ Variance } & \multicolumn{4}{|c|}{ Variance } \\
\hline$\omega$ & $\begin{array}{c}61.319 * * \\
(7.651)\end{array}$ & $\begin{array}{c}60.962^{* *} \\
(9.721)\end{array}$ & $\begin{array}{c}57.284^{* *} \\
(7.540)\end{array}$ & $\begin{array}{c}6.028 * * \\
(5.835)\end{array}$ & $\begin{array}{c}38.696^{* *} \\
(6.786)\end{array}$ & $\begin{array}{c}41.166^{* *} \\
(6.854)\end{array}$ & $\begin{array}{c}40.891^{* *} \\
(7.065)\end{array}$ & $\begin{array}{l}4.402 * * \\
(5.669)\end{array}$ & $\begin{array}{c}0.297^{* *} \\
(5.101)\end{array}$ & $\begin{array}{c}0.337 * * \\
(5.332)\end{array}$ & $\begin{array}{c}0.366^{* *} \\
(5.709)\end{array}$ & $\begin{array}{l}0.075^{*} \\
(2.202)\end{array}$ \\
\hline$\alpha$ & $\begin{array}{c}0.120 * * \\
(7.658)\end{array}$ & $\begin{array}{c}0.193 * * \\
(9.618)\end{array}$ & $\begin{array}{c}0.110 * * \\
(7.476)\end{array}$ & $\begin{array}{c}0.097 * * \\
(7.307)\end{array}$ & $\begin{array}{c}0.007 \\
(0.517)\end{array}$ & $\begin{array}{c}0.010 \\
(0.688)\end{array}$ & $\begin{array}{c}0.011 \\
(0.874)\end{array}$ & $\begin{array}{c}0.016 \\
(1.578)\end{array}$ & $\begin{array}{c}0.173 * * \\
(8.388)\end{array}$ & $\begin{array}{c}0.180 * * \\
(8.188)\end{array}$ & $\begin{array}{c}0.180 * * \\
(8.548)\end{array}$ & $\begin{array}{c}0.172 * * \\
(8.703)\end{array}$ \\
\hline$\gamma$ & - & - & - & - & $\begin{array}{c}0.196 * * \\
(7.615)\end{array}$ & $\begin{array}{c}0.195 * * \\
(7.470)\end{array}$ & $\begin{array}{c}0.179 * * \\
(6.579)\end{array}$ & $\begin{array}{c}0.179 * * \\
(6.806)\end{array}$ & $\begin{array}{l}-0.171^{* *} \\
(-10.504)\end{array}$ & $\begin{array}{l}-0.168 * * \\
(-10.276)\end{array}$ & $\begin{array}{l}-0.158 * * \\
(-9.356)\end{array}$ & $\begin{array}{l}-0.128 * * \\
(-8.541)\end{array}$ \\
\hline$\beta$ & $\begin{array}{l}0.762 * * \\
(31.706)\end{array}$ & $\begin{array}{l}0.683 * * \\
(33.207)\end{array}$ & $\begin{array}{l}0.778 * * \\
(33.063)\end{array}$ & $\begin{array}{l}0.840 * * \\
(50.839)\end{array}$ & $\begin{array}{c}0.828 * * \\
(46.716)\end{array}$ & $\begin{array}{l}0.821 * * \\
(43.776)\end{array}$ & $\begin{array}{l}0.824 * * \\
(44.102)\end{array}$ & $\begin{array}{l}0.859 * * \\
(59.717)\end{array}$ & $\begin{array}{l}0.931 * * \\
(95.901)\end{array}$ & $\begin{array}{l}0.924 * * \\
(86.602)\end{array}$ & $\begin{array}{l}0.919 * * \\
(85.340)\end{array}$ & $\begin{array}{c}0.954 * * \\
(133.838)\end{array}$ \\
\hline Second moment & 0.882 & 0.876 & 0.888 & 0.937 & 0.926 & 0.919 & 0.914 & 0.949 & - & - & - & - \\
\hline
\end{tabular}

Notes: t-values are in parentheses; * and ** indicate significance at the $5 \%$ and $1 \%$ levels, respectively; $\alpha+\beta<1$ is the second moment condition for $\operatorname{GARCH}(1,1) ; \alpha+\beta+\frac{\gamma}{2}<1$ is the second moment condition for $\operatorname{GJR}(1,1)$. 
Table 6: Conditional Volatility Models for the Daily Change Rate of the Number of Individual-type Chinese Tourists

\begin{tabular}{|c|c|c|c|c|c|c|c|c|c|c|c|c|}
\hline \multirow{2}{*}{ Model } & \multicolumn{4}{|c|}{ GARCH $(1,1)$} & \multicolumn{4}{|c|}{$\operatorname{GJR}(1,1)$} & \multicolumn{4}{|c|}{ EGARCH $(1,1)$} \\
\hline & $\operatorname{HAR}(1)$ & $\operatorname{HAR}(1,7)$ & $\operatorname{HAR}(1,7,28)$ & ES & $\operatorname{HAR}(1)$ & $\operatorname{HAR}(1,7)$ & $\operatorname{HAR}(1,7,28)$ & ES & $\operatorname{HAR}(1)$ & $\operatorname{HAR}(1,7)$ & $\operatorname{HAR}(1,7,28)$ & ES \\
\hline Coefficient & \multicolumn{4}{|c|}{ Mean } & \multicolumn{4}{|c|}{ Mean } & \multicolumn{4}{|c|}{ Mean } \\
\hline$\rho_{0}$ & $\begin{array}{c}0.368 \\
(0.816)\end{array}$ & $\begin{array}{c}0.309 \\
(0.646)\end{array}$ & $\begin{array}{c}0.112 \\
(0.231)\end{array}$ & $\begin{array}{c}0.374 \\
(0.829)\end{array}$ & $\begin{array}{c}0.499 \\
(0.986)\end{array}$ & $\begin{array}{c}0.601 \\
(1.174)\end{array}$ & $\begin{array}{c}0.426 \\
(0.821)\end{array}$ & $\begin{array}{c}0.503 \\
(0.995)\end{array}$ & $\begin{array}{c}0.523 \\
(1.116)\end{array}$ & $\begin{array}{c}0.698 \\
(1.444)\end{array}$ & $\begin{array}{c}0.451 \\
(0.910)\end{array}$ & $\begin{array}{c}0.491 \\
(1.042)\end{array}$ \\
\hline$\rho_{1}$ & $\begin{array}{c}-0.165^{* * *} \\
(-5.747)\end{array}$ & $\begin{array}{c}-0.150 * * * \\
(-4.930)\end{array}$ & $\begin{array}{c}-0.142^{* * *} \\
(-4.631)\end{array}$ & $\begin{array}{c}-0.165^{* * *} \\
(-6.001)\end{array}$ & $\begin{array}{c}-0.170 * * * \\
(-5.961)\end{array}$ & $\begin{array}{c}-0.159 * * * \\
(-5.354)\end{array}$ & $\begin{array}{c}-0.152^{* * *} \\
(-5.101)\end{array}$ & $\begin{array}{c}-0.169 * * * \\
(-6.166)\end{array}$ & $\begin{array}{c}-0.161 * * * \\
(-6.127)\end{array}$ & $\begin{array}{c}-0.152 * * * \\
(-5.644)\end{array}$ & $\begin{array}{c}-0.149 * * * \\
(-5.440)\end{array}$ & $\begin{array}{c}-0.160 * * * \\
(-6.273)\end{array}$ \\
\hline$\rho_{2}$ & - & $\begin{array}{c}-0.211 * * * \\
(-2.650)\end{array}$ & $\begin{array}{c}-0.163^{*} \\
(-1.823)\end{array}$ & - & - & $\begin{array}{c}-0.250 * * * \\
(-2.789)\end{array}$ & $\begin{array}{c}-0.203 * * \\
(-2.076)\end{array}$ & - & - & $\begin{array}{c}-0.246 * * * \\
(-2.928)\end{array}$ & $\begin{array}{c}-0.210 * * \\
(-2.490)\end{array}$ & - \\
\hline$\rho_{3}$ & - & - & $\begin{array}{c}-0.555^{* * *} \\
(-2.616)\end{array}$ & - & - & - & $\begin{array}{c}-0.604^{* * *} \\
(-2.867)\end{array}$ & - & - & - & $\begin{array}{c}-0.469 * * * \\
(-2.725)\end{array}$ & - \\
\hline Coefficient & \multicolumn{4}{|c|}{ Variance } & \multicolumn{4}{|c|}{ Variance } & \multicolumn{4}{|c|}{ Variance } \\
\hline$\omega$ & $\begin{array}{c}133.424 * * * \\
(8.236)\end{array}$ & $\begin{array}{c}129.164 * * * \\
(7.837)\end{array}$ & $\begin{array}{c}126.171^{* * *} \\
(7.674)\end{array}$ & $\begin{array}{c}131.715^{* * *} \\
(8.207)\end{array}$ & $\begin{array}{c}122.268 * * * \\
(7.980)\end{array}$ & $\begin{array}{c}99.800 * * * \\
(7.695)\end{array}$ & $\begin{array}{c}95.188 * * * \\
(7.635)\end{array}$ & $\begin{array}{c}120.541^{* * *} \\
(7.958)\end{array}$ & $\begin{array}{c}0.740 * * * \\
(5.699)\end{array}$ & $\begin{array}{c}0.614 * * * \\
(5.142)\end{array}$ & $\begin{array}{c}0.617 * * * \\
(5.104)\end{array}$ & $\begin{array}{c}0.736 * * * \\
(5.681)\end{array}$ \\
\hline$\alpha$ & $\begin{array}{c}0.285 * * * \\
(9.754)\end{array}$ & $\begin{array}{c}0.274 * * * \\
(9.615)\end{array}$ & $\begin{array}{c}0.267 * * * \\
(9.610)\end{array}$ & $\begin{array}{c}0.284 * * * \\
(9.773)\end{array}$ & $\begin{array}{c}0.305^{* * *} \\
(7.873)\end{array}$ & $\begin{array}{c}0.311^{* * *} \\
(7.719)\end{array}$ & $\begin{array}{c}0.308 * * * \\
(7.794)\end{array}$ & $\begin{array}{c}0.303^{* * *} \\
(7.872)\end{array}$ & $\begin{array}{c}0.460 * * * \\
(15.648)\end{array}$ & $\begin{array}{c}0.440 * * * \\
(15.648)\end{array}$ & $\begin{array}{c}0.436 * * * \\
(15.798)\end{array}$ & $\begin{array}{c}0.459 * * * \\
(15.668)\end{array}$ \\
\hline$\gamma$ & - & - & - & - & $\begin{array}{c}-0.047 \\
(-1.123)\end{array}$ & $\begin{array}{l}-0.104 * * \\
(-2.402)\end{array}$ & $\begin{array}{c}-0.113^{* * *} \\
(-2.657)\end{array}$ & $\begin{array}{c}-0.047 \\
(-1.122)\end{array}$ & $\begin{array}{c}0.031 \\
(1.563)\end{array}$ & $\begin{array}{l}0.051^{* *} \\
(2.538)\end{array}$ & $\begin{array}{l}0.051^{* *} \\
(2.556)\end{array}$ & $\begin{array}{c}0.029 \\
(1.482)\end{array}$ \\
\hline$\beta$ & $\begin{array}{c}0.514 * * * \\
(13.503)\end{array}$ & $\begin{array}{c}0.531 * * * \\
(13.331)\end{array}$ & $\begin{array}{c}0.542 * * * \\
(13.938)\end{array}$ & $\begin{array}{c}0.518 * * * \\
(13.683)\end{array}$ & $\begin{array}{c}0.539 * * * \\
(15.133)\end{array}$ & $\begin{array}{c}0.599 * * * \\
(19.748)\end{array}$ & $\begin{array}{r}0.614 * * * \\
(21.902)\end{array}$ & $\begin{array}{c}0.543^{* * *} \\
(15.385)\end{array}$ & $\begin{array}{c}0.826 * * * \\
(39.893)\end{array}$ & $\begin{array}{c}0.849 * * * \\
(44.192)\end{array}$ & $\begin{array}{c}0.849 * * * \\
(44.113)\end{array}$ & $\begin{array}{c}0.827 * * * \\
(40.016)\end{array}$ \\
\hline Second moment & 0.799 & 0.805 & 0.809 & 0.802 & 0.844 & 0.858 & 0.866 & 0.846 & - & - & - & - \\
\hline
\end{tabular}

Notes: t-values are in parentheses; ${ }^{*}, *$ and $* * *$ indicate significance at the $10 \%, 5 \%$ and $1 \%$ levels, respectively; $\alpha+\beta<1$ is the second moment condition for $\operatorname{GARCH}(1,1) ; \alpha+\beta+\frac{\gamma}{2}<1$ is the second moment condition for GJR(1,1). 
Table 7: Conditional Volatility Models for the Daily Change Rate of the Number of Medical-type Chinese Tourists

\begin{tabular}{|c|c|c|c|c|c|c|c|c|c|c|c|c|}
\hline \multirow{2}{*}{ Model } & \multicolumn{4}{|c|}{ GARCH $(1,1)$} & \multicolumn{4}{|c|}{$\operatorname{GJR}(1,1)$} & \multicolumn{4}{|c|}{ EGARCH $(1,1)$} \\
\hline & $\operatorname{HAR}(1)$ & $\operatorname{HAR}(1,7)$ & $\operatorname{HAR}(1,7,28)$ & ES & $\operatorname{HAR}(1)$ & $\operatorname{HAR}(1,7)$ & $\operatorname{HAR}(1,7,28)$ & ES & $\operatorname{HAR}(1)$ & $\operatorname{HAR}(1,7)$ & $\operatorname{HAR}(1,7,28)$ & ES \\
\hline Coefficient & \multicolumn{4}{|c|}{ Mean } & \multicolumn{4}{|c|}{ Mean } & \multicolumn{4}{|c|}{ Mean } \\
\hline$\rho_{0}$ & $\begin{array}{c}0.013 \\
(0.008)\end{array}$ & $\begin{array}{c}-0.209 \\
(-0.135)\end{array}$ & $\begin{array}{c}-0.446 \\
(-0.285)\end{array}$ & $\begin{array}{c}0.286 \\
(0.468)\end{array}$ & $\begin{array}{c}-2.146 \\
(-1.291)\end{array}$ & $\begin{array}{c}-2.334 \\
(-1.471)\end{array}$ & $\begin{array}{c}-2.454 \\
(-1.551)\end{array}$ & $\begin{array}{c}-0.546 \\
(-0.992)\end{array}$ & $\begin{array}{c}-5.596 * * * \\
(-3.164)\end{array}$ & $\begin{array}{c}-4.940 * * * \\
(-3.191)\end{array}$ & $\begin{array}{l}-3.796 * * \\
(-2.375)\end{array}$ & $\begin{array}{c}-1.608 * * * \\
(-3.208)\end{array}$ \\
\hline$\rho_{1}$ & $\begin{array}{c}-0.406 * * * \\
(-18.390)\end{array}$ & $\begin{array}{c}-0.309 * * * \\
(-13.343)\end{array}$ & $\begin{array}{c}-0.268^{* * *} \\
(-11.110)\end{array}$ & $\begin{array}{c}0.034 \\
(1.392)\end{array}$ & $\begin{array}{c}-0.405^{* * *} \\
(-18.423)\end{array}$ & $\begin{array}{c}-0.298 * * * \\
(-12.984)\end{array}$ & $\begin{array}{c}-0.259 * * * \\
(-10.995)\end{array}$ & $\begin{array}{c}0.021 \\
(0.993)\end{array}$ & $\begin{array}{c}-0.391 * * * \\
(-18.795)\end{array}$ & $\begin{array}{c}-0.285^{* * *} \\
(-12.940)\end{array}$ & $\begin{array}{c}-0.258^{* * *} \\
(-11.221)\end{array}$ & $\begin{array}{l}0.036 * \\
(1.645)\end{array}$ \\
\hline$\rho_{2}$ & - & $\begin{array}{c}-1.289 * * * \\
(-10.497)\end{array}$ & $\begin{array}{c}-0.997^{* * *} \\
(-7.815)\end{array}$ & - & - & $\begin{array}{c}-1.298 * * * \\
(-11.359)\end{array}$ & $\begin{array}{c}-0.978^{* * *} \\
(-8.101)\end{array}$ & - & - & $\begin{array}{c}-1.283^{* * *} \\
(-11.803)\end{array}$ & $\begin{array}{c}-0.971^{* * *} \\
(-7.818)\end{array}$ & - \\
\hline$\rho_{3}$ & - & - & $\begin{array}{c}-3.406^{* * *} \\
(-6.733)\end{array}$ & - & - & - & $\begin{array}{c}-3.368 * * * \\
(-7.338)\end{array}$ & - & - & - & $\begin{array}{c}-3.100^{* * *} \\
(-6.781)\end{array}$ & - \\
\hline Coefficient & \multicolumn{4}{|c|}{ Variance } & \multicolumn{4}{|c|}{ Variance } & \multicolumn{4}{|c|}{ Variance } \\
\hline$\omega$ & $\begin{array}{c}129.660 * * * \\
(3.136)\end{array}$ & $\begin{array}{c}117.469 * * * \\
(3.572)\end{array}$ & $\begin{array}{c}123.801^{* * *} \\
(3.041)\end{array}$ & $\begin{array}{c}3.798 * * * \\
(2.884)\end{array}$ & $\begin{array}{c}112.030 * * * \\
(3.039)\end{array}$ & $\begin{array}{c}96.127 * * * \\
(3.528)\end{array}$ & $\begin{array}{c}105.429 * * * \\
(3.293)\end{array}$ & $\begin{array}{c}1.032 \\
(0.638)\end{array}$ & $\begin{array}{c}0.082^{* *} \\
(2.371)\end{array}$ & $\begin{array}{c}0.099 * * * \\
(3.554)\end{array}$ & $\begin{array}{c}0.090 * * \\
(2.248)\end{array}$ & $\begin{array}{c}0.057 * * * \\
(2.670)\end{array}$ \\
\hline$\alpha$ & $\begin{array}{c}0.053^{* * *} \\
(5.710)\end{array}$ & $\begin{array}{c}0.045^{* * *} \\
(5.004)\end{array}$ & $\begin{array}{c}0.048 * * * \\
(5.099)\end{array}$ & $\begin{array}{c}0.014 * * * \\
(4.274)\end{array}$ & $\begin{array}{c}0.006 \\
(0.499)\end{array}$ & $\begin{array}{c}-0.009 \\
(-0.861)\end{array}$ & $\begin{array}{c}-0.009 \\
(-0.959)\end{array}$ & $\begin{array}{c}-0.019 * * * \\
(-5.009)\end{array}$ & $\begin{array}{c}0.023^{* *} \\
(2.212)\end{array}$ & $\begin{array}{c}0.032 * * * \\
(3.087)\end{array}$ & $\begin{array}{c}0.061^{* * *} \\
(4.176)\end{array}$ & $\begin{array}{c}0.003 \\
(0.702)\end{array}$ \\
\hline$\gamma$ & - & - & - & - & $\begin{array}{c}0.090 * * * \\
(3.748)\end{array}$ & $\begin{array}{c}0.100 * * * \\
(4.904)\end{array}$ & $\begin{array}{c}0.106 * * * \\
(5.204)\end{array}$ & $\begin{array}{c}0.187 * * * \\
(7.486)\end{array}$ & $\begin{array}{c}-0.181 * * * \\
(-7.996)\end{array}$ & $\begin{array}{c}-0.141 * * * \\
(8.055)\end{array}$ & $\begin{array}{c}-0.110 * * * \\
(-7.514)\end{array}$ & $\begin{array}{c}-0.171^{* * *} \\
(-14.486)\end{array}$ \\
\hline$\beta$ & $\begin{array}{c}0.924 * * * \\
(69.251)\end{array}$ & $\begin{array}{c}0.933 * * * \\
(76.042)\end{array}$ & $\begin{array}{c}0.928 * * * \\
(65.340)\end{array}$ & $\begin{array}{l}0.978 * * * \\
(190.764)\end{array}$ & $\begin{array}{c}0.932 * * * \\
(74.288)\end{array}$ & $\begin{array}{c}0.944 * * * \\
(87.024)\end{array}$ & $\begin{array}{c}0.939 * * * \\
(79.341)\end{array}$ & $\begin{array}{c}0.958 * * * \\
(140.178)\end{array}$ & $\begin{array}{l}0.989 * * * \\
(278.802)\end{array}$ & $\begin{array}{l}0.986 * * * \\
(337.820)\end{array}$ & $\begin{array}{l}0.984 * * * \\
(198.612)\end{array}$ & $\begin{array}{l}0.991 * * * \\
(367.660)\end{array}$ \\
\hline Second moment & 0.977 & 0.978 & 0.976 & 0.992 & 0.977 & 0.994 & 0.992 & 1.033 & - & - & - & - \\
\hline
\end{tabular}

Notes: t-values are in parentheses; ${ }^{*}, *$ and $* * *$ indicate significance at the $10 \%, 5 \%$ and $1 \%$ levels, respectively; $\alpha+\beta<1$ is the second moment condition for $\operatorname{GARCH}(1,1) ; \alpha+\beta+\frac{\gamma}{2}<1$ is the second moment condition for GJR(1,1). 


\section{References}

Black, F., 1976, “Studies of Stock Market Volatility Changes”, in Proceedings of 1976 American Statistical Association, Business and Economic Statistics Section, Washington, DC, USA.

Bollerslev, T., 1986, “Generalized Autoregressive Conditional Heteroskedasticity”, Journal of econometrics, 31(3), 307-327.

Butler, R.W., 1998, “Seasonality in Tourism: Issues and Implications”, The Tourist Review, 53, 18-24.

Chang, C.-L. and M. McAleer, 2009, "Daily Tourist Arrivals, Exchange Rates and Volatility for Korea and Taiwan”, Korean Economic Review, 25, 241-267.

Chang, C.-L. and M. McAleer, 2012, “Aggregation, Heterogeneous Autoregression and Volatility of Daily International Tourist Arrivals and Exchange Rates”, Japanese Economic Review, 63, 397-419.

Chang, C.-L. and M. McAleer, 2017, “The Correct Regularity Condition and Interpretation of Asymmetry in EGARCH”, Economics Letters, 161, 52-55.

Chang, C.-L., M. McAleer, and C. Lim, 2012, "Modelling the Volatility in Short and Long Haul Japanese Tourist Arrivals to New Zealand and Taiwan”, International Journal of Tourism Sciences, 12, 1-24.

Chang, C.-L., M. McAleer, and D.J. Slottje, 2009, “Modelling International Tourist Arrivals and Volatility: An Application to Taiwan”, in D. Slottje (ed.), Quantifying Consumer Preferences (pp. 303-332), Bingley: Emerald Group Publishing.

Corsi, F., 2009, “A Simple Approximate Long-memory Model of Realized Volatility”, Journal of Financial Econometrics, 7(2), 174-196.

Dacorogna, M.M., U.A. Müller, R.D. Davé, R.B. Olsen, and O.V. Pictet, 1998, "Modelling Short-term Volatility with GARCH and HARCH Models", in Dunis, C. and B. Zhou (Eds.), Nonlinear Modelling of High Frequency Financial Time Series (pp. 161-176), Chichester: Wiley.

Divino, J.A. and M. McAleer, 2010, "Modelling and Forecasting Daily International Mass Tourism to Peru”, Tourism Management, 31, 846-854.

Engle, R.F., 1982, “Autoregressive Conditional Heteroscedasticity with Estimates of 
the Variance of United Kingdom Inflation”, Econometrica, 50, 987-1007.

Glosten, L., R. Jagannathan, and D. Runkle, 1992, “On the Relation between the Expected Value and Volatility of Nominal Excess Return on Stocks”, Journal of Finance, 46, 1779-1801.

Ling, S. and M. McAleer, 2003, “Asymptotic Theory for a Vector ARMA-GARCH Model”, Economic Theory, 19, 278-308.

Ling, S. and M. McAleer, 2010, “A General Asymptotic Theory for Time-series Models”, Statistica Neerlandica, 64(1), 97-111.

McAleer, M., 2015, “The Fundamental Equation in Tourism Finance”, Journal of Risk and Financial Management, 8, 369-374.

McAleer, M. and C. M. Hafner, 2014, “A One Line Derivation of EGARCH”, Econometrics, 2(2), 92-97.

McAleer, M. and M.C. Medeiros, 2008, “A Multiple Regime Smooth Transition Heterogeneous Autoregressive Model for Long Memory and Asymmetries”, Journal of Econometrics, 147(1), 104-119.

McAleer, M., 2014, “Asymmetry and Leverage in Conditional Volatility Models”, Econometrics, 2(3), 145-150.

Müller, U.A., M.M. Dacorogna, R.D. Davé, O.V. Pictet, R.B. Olsen, and J.R. Ward, 1993, "Fractals and Intrinsic Time: A Challenge to Econometricians", in Proceedings of 39th International AEA Conference on Real Time Econometrics, Luxembourg.

Nelson, D.B., 1990, “ARCH Models as Diffusion Approximations”, Journal of econometrics, 45(1-2), 7-38.

Nelson, D.B., 1991, “Conditional Heteroscedasticity in Asset Returns: A New Approach”, Econometrica, 59, 347-370.

Shareef, R. and M. McAleer, 2005, "Modelling International Tourism Demand and Volatility in Small Island Tourism Economies”, International Journal of Tourism Research, 7, 313-333.

Shareef, R. and M. McAleer, 2007, "Modelling the Uncertainty in Monthly International Tourist Arrivals to the Maldives”, Tourism Management, 28, 23-45.

Shephard, N., 1996, "Statistical Aspects of ARCH and Stochastic Volatility" in Barndorff-Nielsen, O.E., D.R. Cox, and D.V. Hinkley (Eds.), Statistical Models in 
Econometrics, Finance and Other Fields (pp. 1-67), London: Chapman \& Hall.

Taiwan Tourism Bureau, “Statistic Data”, Retrieved 11 March, 2018, form: http://admin.taiwan.net.tw/. (in Chinese)

Tsay, R.S., 1987, “Conditional Heteroscedastic Time Series Models”, Journal of the American Statistical association, 82(398), 590-604.

UNWTO, 2017, “UNWTO Tourism Highlights, 2017 Edition”, Retrieved 11 March, 2018, available from: https://www.e-unwto.org/doi/pdf/10.18111/9789284419029.

WTTC, 2017, “Travel \& Tourism Economic Impact 2016 Taiwan”, Retrieved 11 March, 2018,

available

from: https://www.wttc.org/-/media/files/reports/economic-impact-research/countri es-2017/taiwan2017.pdf. 